University of Texas at El Paso

\title{
DigitalCommons@UTEP
}

Open Access Theses \& Dissertations

2009-01-01

\section{Correlation Between Microstructures and Oxidation Resistance in Zr-Nb-Ti Alloys}

Clemente Jose Parga

University of Texas at El Paso, cjparga@miners.utep.edu

Follow this and additional works at: https://digitalcommons.utep.edu/open_etd

\section{Recommended Citation}

Parga, Clemente Jose, "Correlation Between Microstructures and Oxidation Resistance in Zr-Nb-Ti Alloys" (2009). Open Access Theses \& Dissertations. 2750.

https://digitalcommons.utep.edu/open_etd/2750

This is brought to you for free and open access by DigitalCommons@UTEP. It has been accepted for inclusion in Open Access Theses \& Dissertations by an authorized administrator of DigitalCommons@UTEP. For more information, please contact lweber@utep.edu. 
CORRELATION BETWEEN MICROSTRUCTURES AND OXIDATION RESISTANCE IN

Zr-Nb-Ti ALLOYS

CLEMENTE JOSÉ PARGA

Department of Metallurgical and Materials Engineering

APPROVED:

Shailendra K. Varma, Ph.D., Chair

Luis Trueba, Ph.D.

Juan C. Noveron, Ph.D.

Patricia D. Witherspoon, Ph.D.

Dean of the Graduate School 
Dedicated to my parents, Clemente \& María, my brothers, Luis \& Daniel, and to my love, Cintia. 
Zr-Nb-Ti ALLOYS

By

CLEMENTE JOSÉ PARGA, B.S. (MME)

\author{
Presented to the Faculty of the Graduate School of \\ The University of Texas at El Paso \\ in Partial Fulfillment \\ of the Requirements \\ for the Degree of
}

MASTER OF SCIENCE

Department of Metallurgical and Materials Engineering

THE UNIVERSITY OF TEXAS AT EL PASO

December 2009 


\section{ACKNOWLEDGEMENTS}

To start with, I would like to thank Dr. S.K. Varma for all his support and mentoring throughout my master's degree, it has been an honor being part of his high temperature materials development research team. Also, I would like to thank Dr. Luis Trueba and Dr. Juan C. Noveron for accepting the invitation to be part of my thesis committee. Furthermore, I thank Dr. L.E. Murr for accepting me into the metallurgical and materials engineering master's degree, for all the knowledge in materials science, and life advice. Moreover, I appreciate and acknowledge the support of the entire research team, special thanks to Ben and Julieta for their help, advice and support.

Moreover, I would like to thanks Dave Brown for making sure all the equipment was up and running, and for his help in setting up some experiments. Finally, I thank the entire metallurgical and materials engineering department for their support, and always making us feel part of a big family. I always found warm caring help and support from its faculty and staff.

Finally, I want to acknowledge the funding of this project from the Department of Energy of the U.S.A. under grant DE-FG26-05NT42491, Dr. Patricia Rawls is the program manager. 


\begin{abstract}
Oxidation behavior of $\mathrm{Zr}-10 \mathrm{Nb}-10 \mathrm{Ti}$ and $\mathrm{Zr}-10 \mathrm{Nb}-20 \mathrm{Ti}$ (compositions are in atomic percent) alloys has been investigated in air between 300 and $700^{\circ} \mathrm{C}$. Higher Ti content in the alloy enhances the oxidation resistance. The calculated isotherms by Pandat ${ }^{\mathrm{TM}}{ }^{[1,2]}$ show that 20Ti enters a 3 phase ( $\alpha \mathrm{Zr}-\mathrm{HCP}, \beta \mathrm{Nb}-\mathrm{BCC}$, and $\beta \mathrm{Zr}-\mathrm{BCC})$ region at $500^{\circ} \mathrm{C}$ while $10 \mathrm{Ti}$ alloy continues to be a 2 phase $(\alpha \mathrm{Zr}$ and $\beta \mathrm{Nb})$ alloy until $550^{\circ} \mathrm{C}$ and then enters the 3 phase $(\alpha \mathrm{Zr}$, $\beta \mathrm{Nb}$, and $\beta \mathrm{Zr}$ ) region. Both alloys have a single phase $\beta \mathrm{Zr}$ solid solution at $700^{\circ} \mathrm{C}$ which is detrimental for the oxidation resistance. $\beta \mathrm{Nb}$-phase greatly contributes to the oxidation resistance in these two alloys. The common oxidation products have been identified as $\mathrm{TiO}_{2}$, $\mathrm{ZrO}_{2}$, and $\mathrm{Nb}_{2} \mathrm{O}_{5}$. Formation of substoichimoetric structures has been observed at lower temperatures. Both alloys suffer from pest oxidation at temperatures between 500 and $550^{\circ} \mathrm{C}$, respectively (20Ti and $10 \mathrm{Ti}$ ), up to $700^{\circ} \mathrm{C}$. XRD indicates strong peaks for monoclinic structure of $\mathrm{ZrO}_{2}$ at temperatures above $600^{\circ} \mathrm{C}$. Vickers micro-hardness measurements for the as-cast alloys and Rockwell Hardness measurements were conducted on the as-cast and after experimental exposure alloys, in order to obtain some sense of the mechanical properties of the alloys. Increased hardness is related to the formation of $\beta \mathrm{Zr}$ phase in the microstructure.
\end{abstract}




\section{TABLE OF CONTENTS}

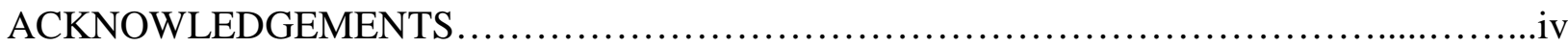

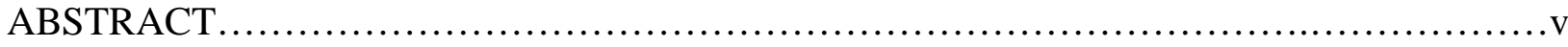

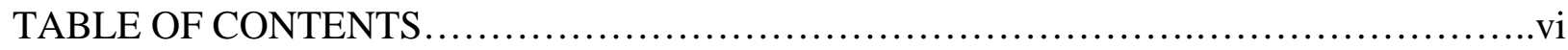

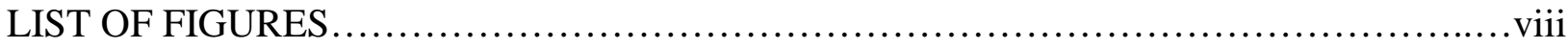

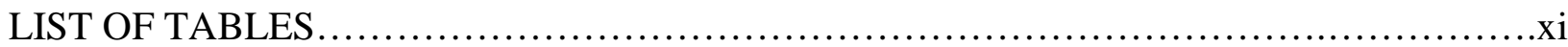

LIST OF EQUATIONS ..........................................................

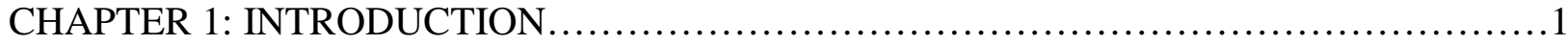

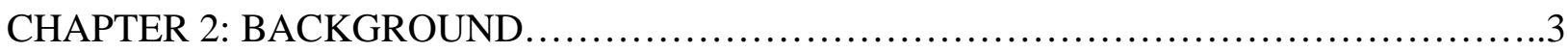

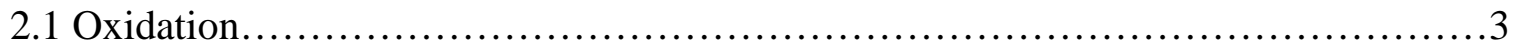

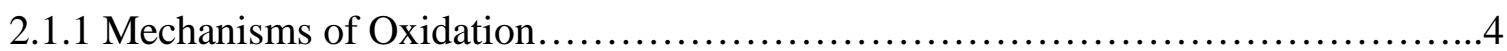

2.1.2 Protective Oxides...................................................6

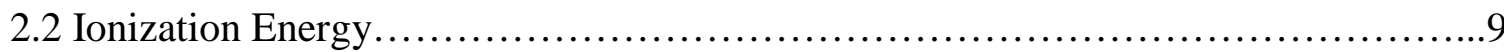

2.3 Metal Selection and Properties.......................................... 10

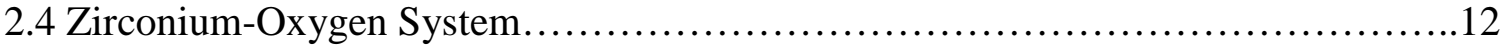

2.5 Oxidation Mechanism of Zirconium-based Alloys................................14

2.6 Alloying Effects on Zirconium..........................................16

CHAPTER 3: EXPERIMENTAL DETAILS ........................................... 19

3.1 Alloy Fabrication..................................................... 19

3.2 Sample Preparation...................................................... 19

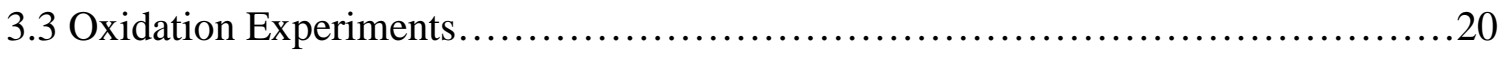

3.4 Sample Characterization.................................................. 
3.4.1 Macrographs of Samples after Oxidation.................................21

3.4.2 Scanning Electron Microscopy, SEM...................................22

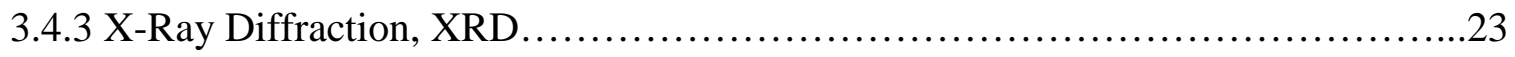

3.4.4 Phase Diagram Modeling..............................................24

3.4.5 Hardness Testing...................................................24

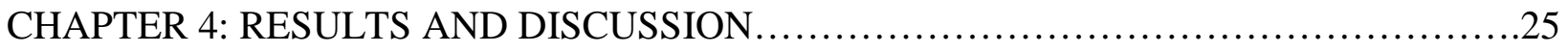

4.1 As-Cast Metal Microstructures................................................

4.1.1 Phase Diagram Modeling and SEM images.................................25

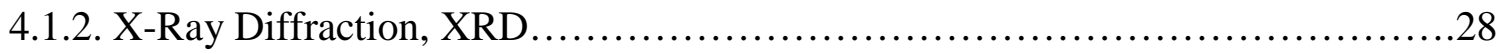

4.2 Short Term Oxidation Curves................................................. 30

4.2.1 After STO Macrographs.....................................................

4.2.2 Microstructures..................................................... 36

4.2.3 Backscatter Electron Imaging .........................................42

4.2.4 X-ray Diffraction (XRD) Results....................................44

4.3 LTO Experiments....................................................46

4.4 Hardness Measurements...............................................48

4.5 Summary and Discussion...............................................

CHAPTER 5: CONCLUSIONS.......................................................

REFERENCES.............................................................. 55

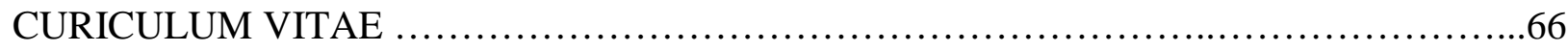




\section{LIST OF FIGURES}

Figure 1. Schematic representation of the oxidation process..................................

Figure 2. Thermodynamic binary phase diagram of $\mathrm{Zr}-\mathrm{O}$ at $1 \mathrm{~atm}[56] \ldots \ldots \ldots \ldots \ldots \ldots \ldots . . . \ldots$

Figure 3. Crystal structure stability of zirconia as a function of temperature and pressure [51]...9

Figure 4. Expansion in the hexagonal closed packed zirconium structure as a function of oxygen

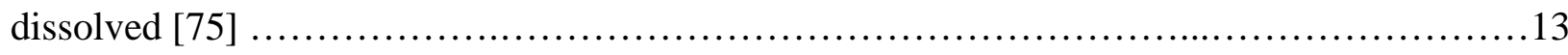

Figure 5. Lattice parameters of different polymorphs of zirconia [76] ........................14

Figure 6. Isothermal sections of the Zr-Ti-Nb system calculated with Pandat ${ }^{\mathrm{TM}}[1,2] \ldots \ldots \ldots \ldots . .26$

Figure 7. As cast microstructure of the (a) 20Ti and (b) 10Ti alloys ...........................27

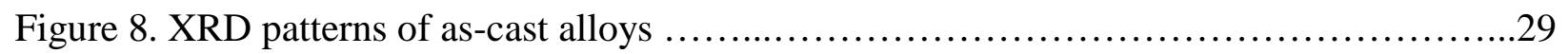

Figure 9. Short term oxidation (STO) graph showing weight change per unit area at different

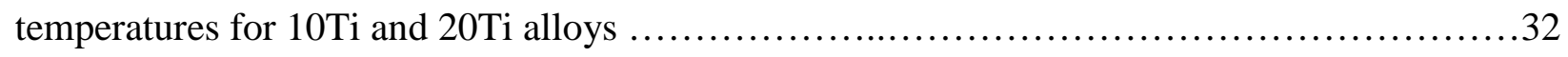

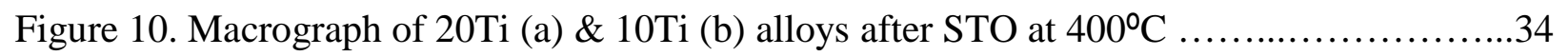


Figure 11. Macrograph of 20Ti (a) \& 10Ti (b) alloys after STO at $500^{\circ} \mathrm{C}$ 35

Figure 12. Macrograph of $20 \mathrm{Ti}$ (a) \& $10 \mathrm{Ti}$ (b) alloys after STO at $550^{\circ} \mathrm{C}$ .35

Figure 13. Macrograph of $10 \mathrm{Ti}$ alloy after STO at 570 (a) and $580^{\circ} \mathrm{C}$ (b) .35

Figure 14. Macrograph of 20Ti (a) \& 10Ti (b) alloys after STO at $600^{\circ} \mathrm{C}$ .36

Figure 15. Macrograph of 20Ti (a) \& 10Ti (b) alloys after STO at 700 .36

Figure 16. Microstructures of (a) 20Ti and (b) 10Ti alloys after STO treatment at $400^{\circ} \mathrm{C}$ .38

Figure 17. Microstructures of (a) 20Ti and (b) $10 \mathrm{Ti}$ alloys after STO treatment at $500^{\circ} \mathrm{C}$ 39

Figure 18. Microstructures of 10Ti alloy after STO treatment at $550^{\circ} \mathrm{C}$ .40

Figure 19. Microstructures of (a) $20 \mathrm{Ti}$ at $562^{\circ} \mathrm{C}$ and (b) $10 \mathrm{Ti}$ at $610^{\circ} \mathrm{C}$ after heating for 2 hours

Figure 20. BSE micrographs of 20Ti (a) and 10Ti (b) alloys showing mictrostructural transformations after STO treatment at 500 and $550^{\circ} \mathrm{C}$, respectively .43 
Figure 21. XRD patterns of the oxidation products of $20 \mathrm{Ti}$ and $10 \mathrm{Ti}$ alloys after $\mathrm{STO}$ at $700^{\circ} \mathrm{C}$

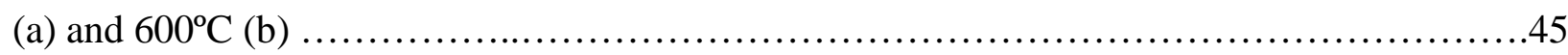

Figure 22. Cyclic long term oxidation (LTO) curves showing the isothermal weight change per unit area for 20Ti and 10Ti alloys for 7 cycles of 24 hours .................................4

Figure 23. Plot of HRA values for 20Ti and 10Ti alloys as a function of temperature and time..50 


\section{LIST OF TABLES}

Table 1. Ionization energies in $\mathrm{eV}$ and $\mathrm{kJ} / \mathrm{mol}$ of the metals studied.......................10

Table 2. Physical and mechanical properties of zirconium, niobium and titanium..............12

Table 3. 20Ti and 10Ti alloys concentration of each element in atomic percent................19

Table 4. Calculation of oxidation rates and mass gain per area values for the LTO experiments

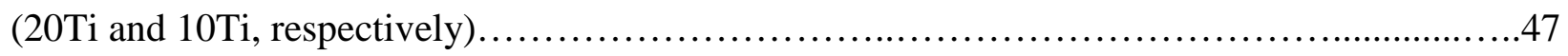

Table 5. Scale "A” Rockwell hardness values for both alloys after different oxidation

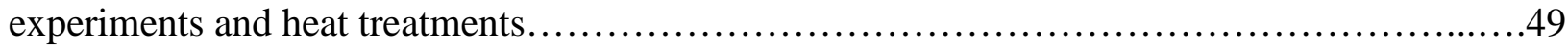




\section{LIST OF EQUATIONS}

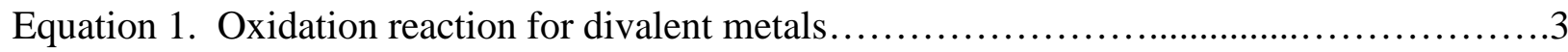

Equation 2. Oxidation reaction for other than divalent metals............................

Equation 3. Oxidation half-reaction occurring at the metal-scale interface..................... 3

Equation 4. Reduction half-reaction occurring at the scale-gas interface...................... 3

Equation 5. Linear oxidation rate expression......................................46 


\section{CHAPTER 1}

\section{INTRODUCTION}

Aerospace and nuclear systems applications require materials with a balance of physical, chemical and mechanical properties that allows an improved performance under very degrading and extreme environments as encountered in nuclear reactor operation conditions; they involve a combination of high temperatures, high pressures caused by superheated steam oxidizing environments, and intense irradiation. ${ }^{[61]}$ Zirconium and its alloys have been chosen as the material of choice in the fuel cladding, tubing, and structural material of nuclear reactors due to its low neutron absorption, high strength, and good corrosion resistance. ${ }^{[63]}$ It has also found application as containment material in the chemical industry due to its good corrosion resistance and strength. Due to an increase in burn up time, higher reactor temperatures, and to improve the performance of zirconium alloys in the event of a severe disaster in nuclear reactors where the core is melted, development of new Zr-based alloys for nuclear power generation and high temperature applications is needed. As a result, a better understanding of the corrosion and/or oxidation behavior, and mechanical properties of zirconium alloyed with other elements is of great interest.

Zirconium- $\mathrm{Nb}$ containing alloys have been widely used as cladding and structural material in nuclear reactors due to its improved corrosion resistance, claimed to be the niobium effect, when added to zirconium. ${ }^{[64]}$ Other studies have been focused on the effect of other moderate additions of different alloying elements i.e., $\mathrm{Sn}, \mathrm{Fe}, \mathrm{Cr}, \mathrm{Al}$, among others, on the properties of zirconium based alloys. Therefore, it is of interest to study the effect of other 
alloying elements, like Titanium, on the oxidation and mechanical properties of zirconium based alloys. Besides alloying, some other techniques, i.e. application of protective coatings and ion implantation, have been used to improve the oxidation resistance of alloys by promoting the formation of a coherent and protective oxide scale on the surface of the metal.

In this study we investigate the oxidation behavior in stagnant air of a niobiumcontaining zirconium alloy with different titanium additions under temperatures from 300 to $700^{\circ} \mathrm{C}$. The alloys under investigation are $\mathrm{Zr}-10 \mathrm{Nb}-10 \mathrm{Ti}$ and $\mathrm{Zr}-10 \mathrm{Nb}-20 \mathrm{Ti}$ in atomic percent. Study of the effect of titanium additions in a $\mathrm{Zr}-10 \mathrm{Nb}$ alloy has been chosen due to its good strength, low density, and passive or protecting oxide formation. Two sets of experiments were performed: (a) heating in air for 24 hours at various temperatures from 300 to $700^{\circ} \mathrm{C}$, short term oxidation (STO) and (b) repeating the 7 cycles of part (a) at a given temperature, long term oxidation (LTO).

The funding of this project has been received from the Department of Energy of the U.S.A. under grant DE-FG26-05NT42491, Dr. Patricia Rawls is the program manager. 


\section{CHAPTER 2}

\section{BACKGROUND}

\subsection{Oxidation}

When an atom, ion, or molecule has become more positively charged, or has lost electrons, we say that it has been oxidized. ${ }^{[22]}$ Deteriorative mechanisms are different for different material types. In metals, there is actual material loss either by dissolution (corrosion) or by the formation of nonmetallic scale or film (oxidation). Oxidation of metal alloys in gaseous atmospheres, normally air, is a phenomenon frequently termed scaling, tarnishing, or dry corrosion. The process of oxide layer formation is of an electrochemical nature, and can be described by the following reaction:

$$
\begin{gathered}
\mathrm{M}+1 / 2 \mathrm{O}_{2} \rightarrow \mathrm{MO} \text { (For divalent metals) (Equation 1) } \\
a \mathrm{M}+b / 2 \mathrm{O}_{2} \rightarrow \mathrm{M}_{a} \mathrm{O}_{b} \text { (For other than divalent metals) (Equation 2) }
\end{gathered}
$$

The previous reaction consists of two half-reactions, which are the oxidation and reduction.

$$
\begin{aligned}
& \mathrm{M} \rightarrow \mathrm{M}^{2+}+2 e^{-}(\text {Oxidation reaction occurs at the metal-scale interface) } \\
& 1 \text { (Equation 3) } \\
& 1 / 2 \mathrm{O}_{2}+2 e^{-} \rightarrow \mathrm{O}^{2-} \text { (Reduction reaction occurs at the scale-gas interface) (Equation 4) }
\end{aligned}
$$

Figure 1 is a schematic representation of the oxidation process: 


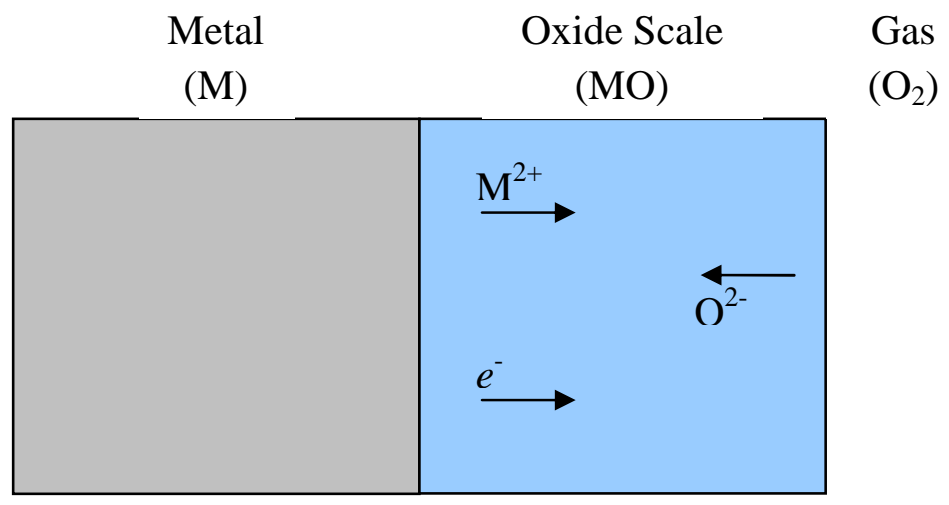

Figure 1. Schematic representation of the oxidation process. ${ }^{[23]}$

In order for the oxide layer to increase in thickness electrons must be conducted to the scale-gas interface; also metal ions must diffuse away from the metal-scale interface, and/or oxygen ions must diffuse toward this same interface. Alternatively, electron holes and vacancies may diffuse instead of electrons and ions. Therefore, the oxide scale serves as an electrolyte through which ions diffuse, and also as an electrical circuit for the passage of electrons. As a result, the scale might protect the metal from rapid oxidation when it acts as a barrier to ionic diffusion and/or electrical conduction. ${ }^{[23]}$

\subsubsection{Mechanisms of Oxidation}

The oxidation of a metal in air or any corrosive environment increases with temperature and takes place under a combination of different physical and chemical processes:

-Initially, there is an adsorption of oxygen atoms in the immediate vicinity of the metal 
substrate surface up to a certain solubility limit that change for every metal and increases with temperature. At this stage oxygen acts as an electron donor in the metal.

-After saturation of the metallic surface and under favorable thermodynamic conditions, nucleation and growth of crystallites, resembling oxide islands on the metal surface, takes place forming a compact and continuous oxide layer that results in lowering of the oxidation rate and further oxidation. The initial oxide film is typically of an amorphous, sub-stoichiometric nature.

-As the oxide grows, tensile and compressive stresses develop at the metal-scale interface, due to mismatches in the lattice parameters and coefficients of thermal expansion between the oxide and the metal substrate, resulting in the crack formation and propagation as a mechanism to relief the localized stresses due to straining of the scale. This leads to changes in the oxidation mechanism of the metal due to the formation of new paths for faster diffusion of oxidizing species, as it is the case with oxygen when the metal oxidizes in air.

Diffusion of ion species and electrons is driven by a combination of the chemical and electrostatic potentials, which determine the oxidation kinetics. Oxidation mechanisms are conformed by three general laws that involve logarithmic, linear, and parabolic oxidation kinetics. The logarithmic behavior is typical of an initial fast oxidation and low temperatures, where oxygen reacts with the metal substrate to form an oxide in order to lower the interfacial energy at the metal/gas interface. The oxidation rate decreases or stabilizes as a result of oxide 
growth or oxide scale thickening that slows down the diffusion of oxygen anions towards the metal/oxide interface. The following stage of oxidation can obey a linear, parabolic, or a combination of the two, oxidation kinetics. Under linear kinetics continued oxidation takes place at a constant rate, it is characterized by the formation of oxide isles on the surface of the metal that do not provide oxidation protection. As oxidation continues, anisotropic growth of the oxides, mismatches due to differences in coefficient of thermal expansion, differences in crystal structure, and composition gradients, among others can lead to cracking, swelling, and spallation of the oxide scale continuing the oxidation of the metal until the sample is completely oxidized or destroyed. Finally, when the oxidation mechanism follows a parabolic behavior, the oxidation rate is gradually decreased due to the formation of a protective oxide scale. Decrease in the diffusion rate takes place due to the formation of a dense coherent oxide scale which impedes the movement of ions; this effect is more prominent as the oxide increases in thickness. ${ }^{[25,44,45]}$

\subsubsection{Protective Oxides}

An oxide's morphology is subject to change under different environments, time exposure, and parent metal alloy composition following energetically favorable transformations. A protective oxide must be able to create an adhesive and compact metal/oxide interface, that grows at a moderate rate, and that is able to self-heal. ${ }^{[25]}$ On the other hand, a protective oxide slows down the oxidation of metallic alloys by acting as a barrier for the diffusion of ions. For example, typical oxides that form readily under exposure to ambient conditions are $\mathrm{Al}_{2} \mathrm{O}_{3}, \mathrm{SiO}_{2}$, and $\mathrm{Cr}_{2} \mathrm{O}_{3}$, they are well-known for their protective behavior; also, other oxides as $\mathrm{ZrO}_{2}, \mathrm{TiO}_{2}$, and $\mathrm{Nb}_{2} \mathrm{O}_{5}$ have been found to have protective behavior under corrosion environments. ${ }^{[50,52,53]}$ 
In order to reduce the degradation of metallic alloys under corrosion or oxidation mechanisms protective coatings and ion implantation have been used as methods to tailor the growth of adherent, stable, protecting scales. $\mathrm{Nb}, \mathrm{Ti}, \mathrm{Zr}$, $\mathrm{Hf}$ and $\mathrm{Nb}+\mathrm{Zr}$ - based coatings have been used as protective scales due to the presence of stable compounds that offer better protection resistance in corrosive environments. ${ }^{[47,48,50]}$ Also, conversion coatings as $\mathrm{Cs}-\mathrm{Zr}-\mathrm{Nb}$ on magnesium alloy AZ91 have been studied and found to have to form a cohesive interface with the substrate, and to improve the corrosion resistance of the magnesium alloy due to the formation of stable compounds of $\mathrm{CeO}_{2}, \mathrm{Ce}_{2} \mathrm{O}_{3}, \mathrm{ZrO}_{2}$, and $\mathrm{Nb}_{2} \mathrm{O}_{5}$. ${ }^{[46]}$ Therefore, by improving and predicting the oxidation resistance of a substrate other parameters such as dimensions and mechanical properties can be maintained avoiding catastrophic failure of structural materials under service conditions.

Furthermore, as an oxide scale coarsens its ability to accommodate stresses due to differences in crystal structure, and coefficients of thermal expansion between forming oxides are of great importance since they will dictate the extent to which this oxide will remain passivating. As a result, metastable oxides with different structures can be formed at nonequilibrium conditions due to high local pressures arising from mechanical compressive stresses in the oxide. For example, different polymorphs of zirconia have been observed, specifically tetragonal and cubic $\mathrm{ZrO}_{2}$, under low temperature oxidation environments along with the stable monoclinic form of $\mathrm{ZrO}_{2}$, even though, these crystal structures are not stable in equilibrium

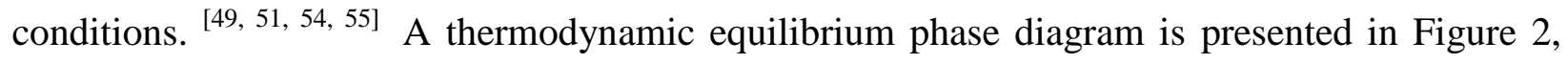
showing different regions of stable structures in the $\mathrm{Zr}-\mathrm{O}$ phase diagram as a function of 
temperature and oxygen concentration.

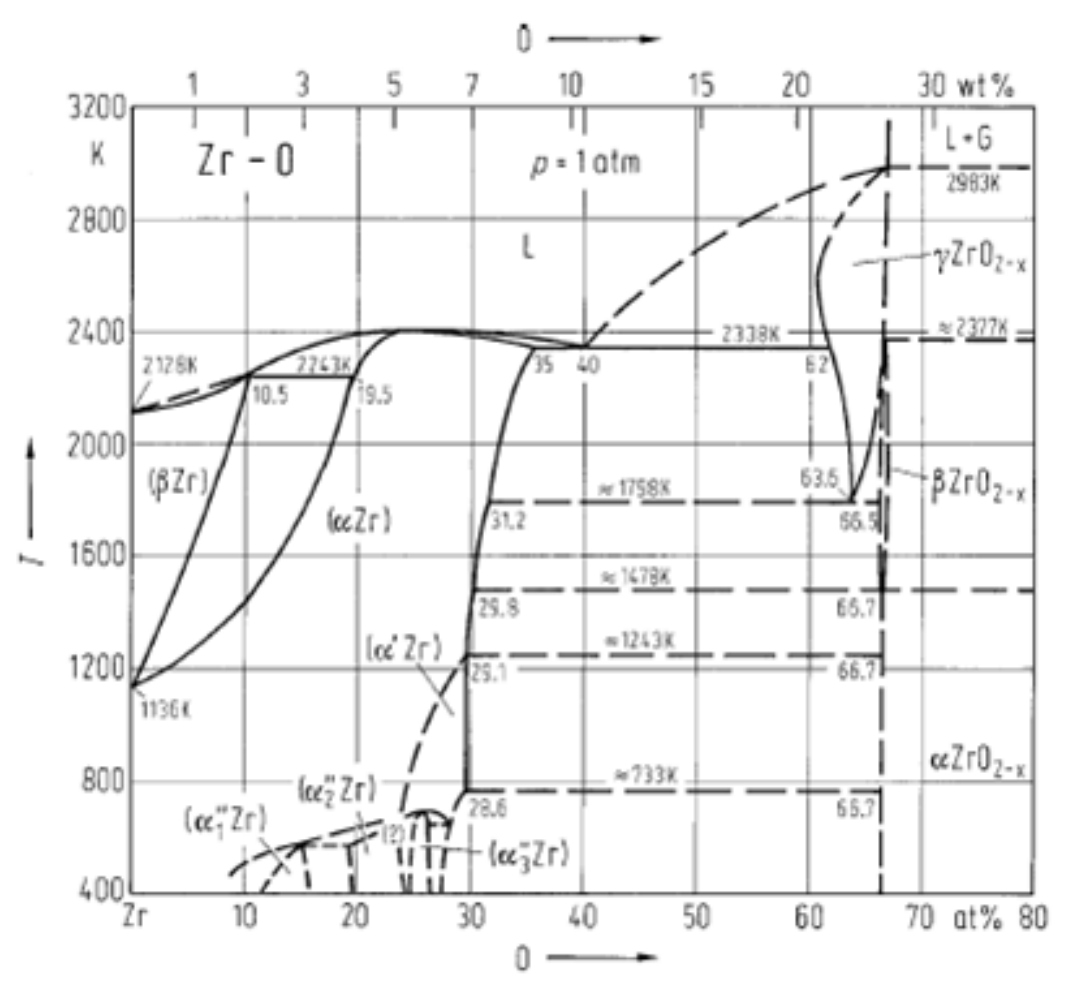

Figure 2. Thermodynamic binary phase diagram of $\mathrm{Zr}-\mathrm{O}$ at $1 \mathrm{~atm} .{ }^{[56]}$

Figure 3 shows another diagram presenting regions of stability of $\mathrm{ZrO}_{2}$ as a function temperature and pressure which provides further evidence on the ability to form thermodynamically non-stable structures under high pressure conditions. 


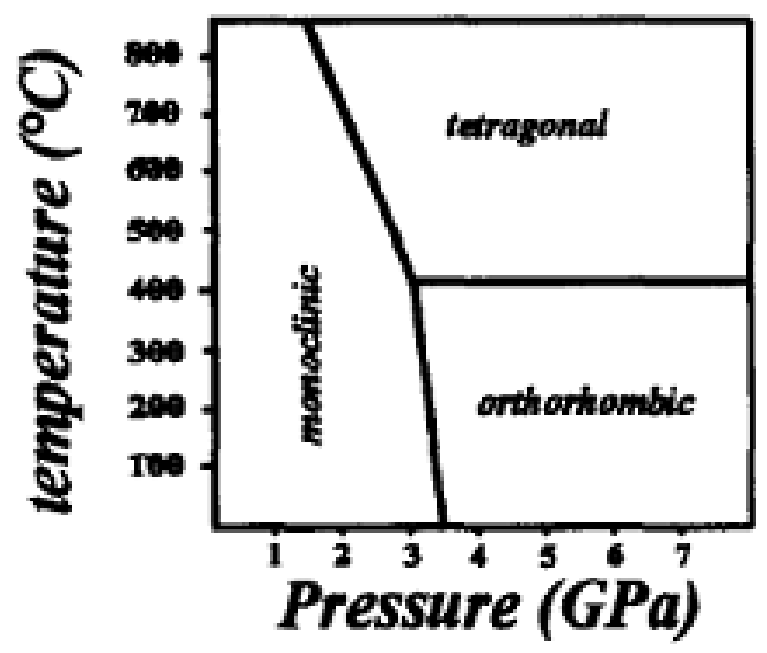

Figure 3. Crystal structure stability of zirconia as a function of temperature and pressure. ${ }^{[51]}$

\subsection{Ionization Energy}

By definition the ionization energy of an atom or ion is the minimum energy required to remove an electron from the ground state of the isolated gaseous or atom. The first ionization energy, $I_{1}$, is the energy needed to remove the first electron from a neutral atom. The greater the ionization energy, the more difficult is to remove an electron. ${ }^{[22]}$ Therefore, this is a property that is extremely important when dealing with the oxidation behavior of metals and alloys; since it dictates to some extent how selective oxidation or corrosion will take place with different metals, alloys and/or compounds at a different rate. The following is a table (Table 1) of the ionization energy of the pure form of the metals pertinent to this study. 
Table 1. Ionization energies in $\mathrm{eV}$ and $\mathrm{kJ} / \mathrm{mol}$ of the metals studied.

\begin{tabular}{|l|l|l|l|}
\hline Atomic number, $\mathrm{Z}$ & Element & Ionization energy, $\mathrm{eV}^{[26]}$ & Ionization energy, $\mathrm{kJ} / \mathrm{mol}^{[27,28]}$ \\
\hline 22 & Titanium & 6.8281 & 658.8 \\
\hline 41 & Niobium & 6.758859 & 652.1 \\
\hline 40 & Zirconium & 6.63390 & 640.1 \\
\hline
\end{tabular}

From the previous table we can see that zirconium has lower ionization energy than the other alloying elements. Therefore by alloying with elements of greater ionization potential it might be possible to improve the oxidation resistance of the pure element since the energy needed to remove an electron from the alloy will be higher when compared to, i.e. pure zirconium, resulting in an increase in oxidation resistance.

\subsection{Metal Selection and Properties}

\section{Niobium}

(Niobe, daughter of Tantalus). Columbium was its previous name (Columbia, name for America) until 1950, after 100 years of controversy, when its present name was adopted by the International Union of Pure and Applied Chemistry. Niobium is a shiny, white, soft, and ductile metal, and turns into a bluish cast color when exposed to air at room temperature for a long time. It has poor oxidation resistance, and starts to oxidize in air at $200^{\circ} \mathrm{C}$. It is used as an alloying element to improve the strength in nonferrous alloys, and the same pertains for carbon and alloy steels. Niobium has been widely used in advanced air frame systems for space program 
applications. ${ }^{[24]}$

\section{Titanium}

(From Latin, Titans, the first sons of the Earth, Greek mythology) In its pure form titanium has a lustrous white metallic appearance. It has a low density, good strength, ease of fabrication, and excellent corrosion resistance. The strength of titanium is comparable to steel, but with the advantage of being $45 \%$ lighter. Moreover, it also is $60 \%$ heavier than aluminum, but double its strength. Titanium alloys are widely used for aircraft and missiles where extreme service temperatures are encountered, and light weight strength is needed. ${ }^{[24]}$

\section{Zirconium}

(From Arabic, zargun, gold color) Its appearance is of a grayish-white lustrous metal. Zirconium has been found to be extremely resistant to the corrosive environment inside atomic reactors, and it allows neutrons to pass through the internal zirconium construction material without appreciable absorption of energy. Zircaloy (Zr-Nb based alloy) is an important alloy developed specifically for nuclear applications. Zirconium has a very high corrosion resistance to common acids and alkalis, sea water, and it is extensively employed in the chemical industry where corrosive agents are used. ${ }^{[24]}$

Table 2 present different physical and mechanical properties related to the metals studied for this thesis. 
Table 2. Physical and mechanical properties of zirconium, niobium and titanium.

\begin{tabular}{|c|c|c|c|}
\hline & Zirconium & Niobium & Titanium \\
\hline $\begin{array}{ll}\text { Structure, } & \text { and lattice } \\
\text { constants in } \AA^{[29-30]} & \end{array}$ & $\begin{array}{l}\mathrm{HCP}(\mathrm{a}=3.230 \\
\mathrm{c}=5.133, \\
\mathrm{c} / \mathrm{a}=1.589) \\
\mathrm{BCC}(\mathrm{a}=3.62)\end{array}$ & $\mathrm{BCC}(\mathrm{a}=3.2972)$ & $\begin{array}{l}\mathrm{HCP}(\mathrm{a}=2.9503, \\
\mathrm{c}=4.6831, \\
\mathrm{c} / \mathrm{a}=1.5873)\end{array}$ \\
\hline Melting Point, ${ }^{\circ} \mathrm{C}^{[24]}$ & 1852 & 2468 & 1660 \\
\hline Density, $\mathrm{g} / \mathrm{cm}^{3[29-30]}$ & 6.49 & 8.58 & 4.505 \\
\hline Yield Strength, $10^{3} \mathrm{psi}^{[29-30]}$ & 15.0 & 38 & 20.7 \\
\hline $\begin{array}{l}\text { Young's Modulus, } 10^{6} \mathrm{psi} \\
\text { [29-30] }\end{array}$ & 11.3 & 15.08 & 15.5 \\
\hline
\end{tabular}

\subsection{Zirconium-Oxygen System}

The binary zirconium oxygen thermodynamic equilibrium phase diagram conforms regions of stability for different metallic zirconium phases $(\alpha-\mathrm{Zr} \& \beta-\mathrm{Zr})$ and several polymorphs of $\mathrm{Zr}-\mathrm{O}$ compounds that are stable at different temperature and composition ranges. Parameters as solubility of oxygen in the hexagonal close packed and base center cubic structures of zirconium can be obtained from the phase diagram. For example, experimental studies have found that $\alpha-Z r$ (hexagonal) has a greater solubility of oxygen when compared to its higher temperature cubic structure. ${ }^{[56-59]}$ As a result of adsorption of oxygen atoms into interstitial sites of metallic zirconium, changes in lattice parameters can be expected to affect the mechanical and physical properties of the metal or alloy. HCP zirconium is known to dissolve interstitially large 
amounts of oxygen into its octahedral sites. The diffusion of the oxygen atoms into the zirconium hexagonal structure causes an expansion of the lattice in the basal plane and the perpendicular axis parameters. This expansion is more prominent in the z-direction or lattice parameter $\mathrm{c}$. As a result, some studies have suggested anisotropic or orientation related changes in the diffusion rate of oxygen in zirconium. ${ }^{[57-59]}$ Figure 4 shows the changes in lattice parameter of $\alpha \mathrm{Zr}$ as a function of oxygen dissolved

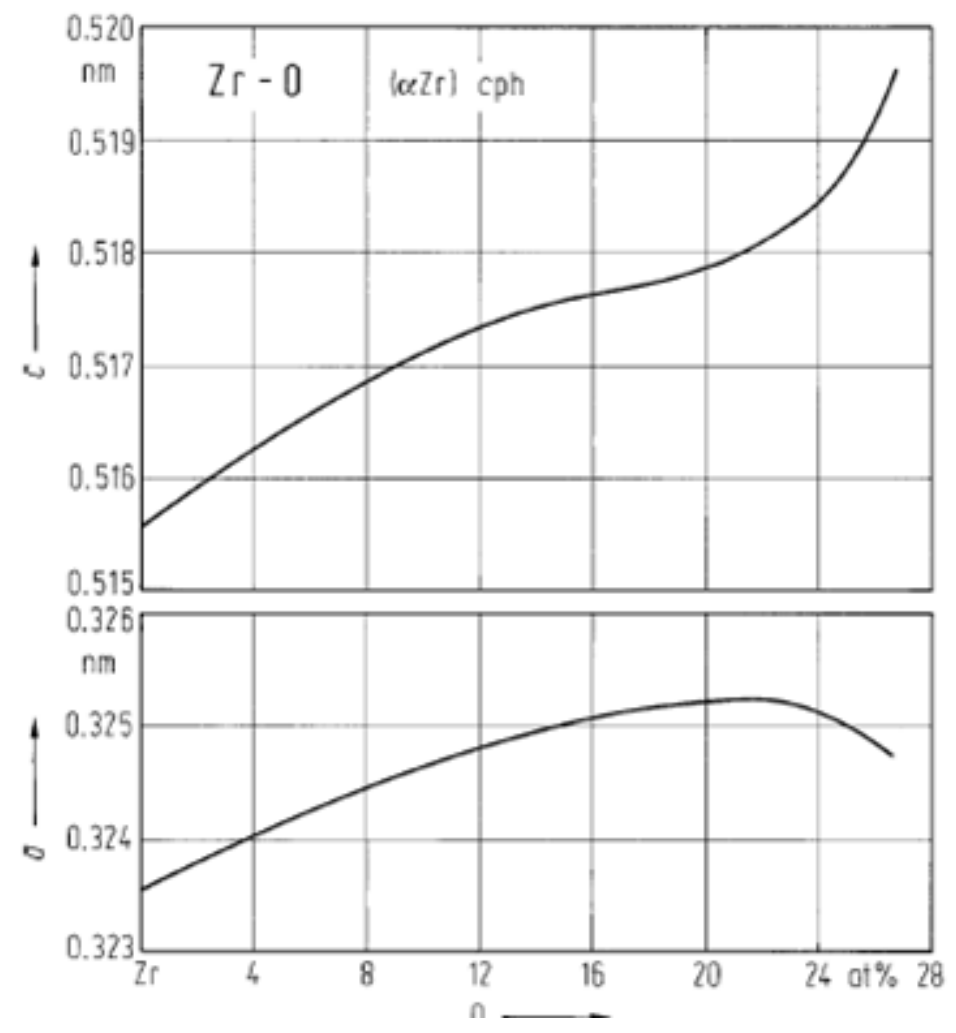

Figure 4. Expansion in the hexagonal closed packed zirconium structure as a function of oxygen dissolved. ${ }^{[75]}$

Different stochiometric structures of zirconia are present in the isobaric $(1 \mathrm{~atm})$ phase diagram as a function of temperature and composition. The following (Figure 5) is a table showing the crystal structure and lattice parameters of the different polymorphs: ${ }^{[56,59,67]}$ 


\begin{tabular}{llllll}
\hline Phase & Structure & Type & $a[\mathrm{~nm}]$ & $b[\mathrm{~nm}]$ & $c[\mathrm{~nm}]$ \\
\hline$\alpha \mathrm{ZrO}$ & mon & & 0.5169 & 0.5232 & 0.5341 \\
$\mathrm{ZZrO}_{2}$ & tetr & $\mathrm{HgI}_{2}$ & 0.35882 & & 0.51882 \\
$\mathrm{ZrO}_{2}$ & cub & $\mathrm{CaF}_{2}$ & 0.509 & & \\
\hline
\end{tabular}

Figure 5. Lattice parameters of different polymorphs of zirconia. ${ }^{[76]}$

Furthermore, other less stable sub-oxides having an oxygen deficiency can be shown in the phase diagrams. These are usually encountered as precursors of more stable $\mathrm{ZrO}_{2}$ compounds in the oxidation process of zirconium. The zirconium sub oxides are considered as pseudocrystalline or amorphous structures which are zirconium rich, and oxygen depleted compounds that contain large amounts of oxygen vacancies. These compounds lack long range order and have been identified as $\mathrm{Zr}_{6} \mathrm{O}, \mathrm{Zr}_{3} \mathrm{O}$, and $\mathrm{Zr}_{2} \mathrm{O}$. ${ }^{[59]}$

\subsection{Oxidation Mechanism of Zirconium-based Alloys}

Studies on the oxidation of zirconium at low temperatures have shown that oxygen is first physi-absorbed on the surface of zirconium by diffusion through interstitial sites and grain boundaries, reaching solid solutions of around $30-35$ at. $\% .{ }^{[54,61]}$ No oxide is formed in this first stage oxygen acts as an electron donor that occupies the octahedral sites of the zirconium structure. Furthermore, when the solubility of oxygen reaches its saturation limit, chemical reactions forma a thin layer of sub-oxides having a protective nature. This initial protective layer slows down the oxidation rate of the substrate by acting as an electrolyte that governs the 
diffusion rate of ions through the scale. The initial sub-oxides have a dark color, and turn to white when $\mathrm{ZrO}_{2}$ is formed. At this stage, the predominant electron transport is by tunneling up to limiting oxide thicknesses and relatively low temperatures $\leq 300^{\circ} \mathrm{C}$; when the critical oxide thickness is reached or at intermediate temperatures, $300^{\circ} \mathrm{C} \leq \mathrm{T} \leq 500^{\circ}$, thermionic emission and concentration gradient diffusion become the mechanisms that drive the ion transport through the oxide scale. The oxide grows by the diffusion of anion species through the oxide scale to react with the substrate at the metal/oxide interface, there is essentially no outward diffusion of cations through the oxide scale. Therefore, movement of the metal/oxide interface takes place in the inward direction. At intermediate temperatures the linear oxidation law governs the oxidation rate of the substrate. Furthermore, previous studies have shown that other allotropes of zirconia can be stabilized in the oxide due to pressures induced by mechanical stresses arising from oxide growth. Furthermore, parameters such as fine grain size and high temperatures are also responsible for stabilized tetragonal $\mathrm{ZrO}_{2}$ coexisting with monoclinic $\mathrm{ZrO}_{2}$. Finally, at temperatures $>500^{\circ} \mathrm{C}$ high stresses are reached and exceed the strength of the cohesion between oxide and metal interface, due to significant difference in the coefficient of linear expansion between the oxide and the metal substrate, cause flaking and/or cracking of the oxide scale; as a result an increase in the oxidation rate is observed due to the formation of new paths for oxygen diffusion and fresh metal exposure. ${ }^{[43,44,45,48,49,51,55,56,-58,61,62,66,69,71] \text { Therefore, repeated }}$ formation of new oxide scale, spallation and cracking (as a mechanism to relief the local stresses), continues until compete oxidation or destruction of the metal substrate takes place. 


\subsection{Alloying Effects on Zirconium}

In reality no metal is in its pure form, because even very sophisticated refining process will not achieve completely pure metals containing only one atom species. These impurities might be in solid solution with the base metal, forming a single phase of the same structure as the parent metal; or they might form a secondary phase with different structure and properties depending on the type of impurity, concentration, and temperature. ${ }^{[23]}$ Alloying is performed in order to improve the properties of the parent metal (mechanical, physical, chemical, electrical, etc.).

A solid solution is formed when the foreign atom added to the base material does not cause changes in crystal structure, and no secondary phases are formed. The alloying element might dissolve into the parent metal acting as a substitutional atom or occupying interstitial sites. Parameters such as atomic size of the atom species, dictate the extent of solubility of an impurity atom in the base metal, traditionally differences in atomic size up to $15 \%$ are accommodated in the solid solution without any structure transformation. Furthermore, solid solubility increases if the two metals have the same crystal structure in its pure form, since no major deformation of the initial structure takes place in order to accommodate foreign atoms. Finally, other factors like electronegativity and valence play a role when dissolving impurity atoms in the base metal. For example, atoms having different electronegativities will tend to form intermetallic compounds instead of solid solutions; also, metals with lower valence will have a tendency to dissolve metals of higher valence. 
Common alloying elements introduced in zirconium to improve its mechanical and corrosion properties are iron, niobium, chromium, vanadium, nickel, tin, silicon, among others. These impurities can be dissolved into the zirconium matrix, form secondary phases or precipitates with different crystal structures, or be implanted on the surface of the base metal. Furthermore, studies on the addition of niobium in the range of $2.5-12.5 \%$ to zirconium have shown an increase in the room temperature yield strength, and ultimate tensile strength from 63.3 to $81.5 \times 10^{3} \mathrm{psi}$, and 87.5 to $102.2 \times 10^{3} \mathrm{psi}$, respectively. On the other hand, additions of titanium to zirconium in range of 3.2 to $35.0 \%$ result in an increase of yield and ultimate tensile strength from 42.5 to $110 \times 10^{3} \mathrm{psi}$, and 85.4 to $138.8 \times 10^{3}$, respectively. ${ }^{[29]}$ At the same time an increase in hardness with respect to the pure zirconium metal are observed. Moreover, by alloying with titanium an improvement in the mechanical properties of the base metal and, due to the low density of titanium, a lighter alloy is obtained.

Furthermore, other studies have shown that niobium implantation on zirconium alloys used in nuclear reactor environments, results in an improvement of the corrosion resistance of the alloy ${ }^{[70]}$; it has been found that when $\mathrm{Nb}_{2} \mathrm{O}_{5}$ is dispersed in the oxide layer it acts a barrier that reduces the migration and dissolution of zirconium, and thus improve the corrosion resistance of the samples. ${ }^{[32,33]}$ Continuing with the niobium effect on zirconium, other studies have found that $\beta-\mathrm{Nb}$ and $\mathrm{Nb}$-rich phases remain unoxidized in the vicinity of the metal/oxide layer, and when they finally oxidize, they form amorphous oxides that have been found to be protective since they act as barrier to ion transport in the oxide layer. ${ }^{[34-40]}$ 
Furthermore, $\mathrm{Zr}-2.5 \mathrm{wt} \% \mathrm{Nb}$ has been used as pressure tube material for CANDU (Canadian) reactors due to its good strength, high corrosion and creep resistance. ${ }^{[3]}$ Modern reactors use alloys containing $\mathrm{Nb}, \mathrm{Zr}-1 \mathrm{wt} \% \mathrm{Nb}-\mathrm{O}{ }^{[4]}$, called $\mathrm{M} 5^{\mathrm{TM}}$, which is similar to the Russian E110 alloy, ZIRLO ${ }^{\mathrm{TM}}{ }^{[5]}$. There are studies that suggest that $\mathrm{Zr}$ additions improve the electrochemical corrosion behavior of Ti-30Nb alloy. ${ }^{[6-9]}$ For example Ti-23Nb-0.7Ta-2Zr-O alloy shows improved corrosion behavior compared to conventional Ti-6Al-4V alloy in Ringer's solution due to the passive film composed of $\mathrm{Ti}, \mathrm{Nb}$, Ta, and $\mathrm{Zr}$. Davidson and Kovacks have found that $\mathrm{Zr}$ addition leads to better corrosion resistance due to the stable oxide layer of Titanium alloys for medical implants. On the other hand, another study suggests that the addition of Zirconium is detrimental to the oxidation resistance compared to Ta additions in the Ti-44AlxNb-2(Ta, Zr) alloys. ${ }^{[9]}$ Also, studies in the past have suggested that corrosion behavior of $\mathrm{Zr}$ $2.5 \% \mathrm{Nb}$ is sensitive to its microstructure ${ }^{[18]}$ and $\mathrm{Zr}$ has a tendency to form passive oxides in $\mathrm{Ti}$ based alloys ${ }^{[8]}$. 


\section{CHAPTER 3}

\section{EXPERIMENTAL DETAILS}

\subsection{Alloy Fabrication}

The Zr-based alloys were prepared by Ames National Laboratory at the Iowa State University using arc melting technique in an argon atmosphere to avoid oxidation of the metals. The base metals used had at least four nines purity (99.99\%). The selected alloys in this study have the following compositions (in atomic percents): $\mathrm{Zr}-10 \mathrm{Nb}-10 \mathrm{Ti}$ (10Ti alloy) and $\mathrm{Zr}-10 \mathrm{Nb}-$ 20Ti (20Ti alloy). Table 3 presents the concentration of each metal, in atomic percent, for the studied alloys.

Table 3. 20Ti and 10Ti alloys concentration of each element in atomic percent.

\begin{tabular}{|l|c|c|c|}
\hline & Zirconium & Niobium & Titanium \\
\hline 20Ti alloy & 70 & 10 & 20 \\
\hline 10Ti alloy & 80 & 10 & 10 \\
\hline
\end{tabular}

Repeated melting process was employed to ensure the complete and uniform miscibility of the pure metals in the liquid condition. The specimens were sectioned from the as cast bars by electric discharge machining (EDM) or spark eroding with final dimension of $8 \times 8 \times 2 \mathrm{~mm}$.

\subsection{Sample Preparation}

The as-cast alloys were prepared for oxidation experiments in the following steps: 
1. Samples were ground down to 600-grit using $\mathrm{SiC}$ sand papers in order to remove oxide impurities and to expose a fresh metallic surface.

2. Four equal sized samples were cut from the original cubes, using a diamond disc in a precision saw machine, for short term oxidation experiments; and bigger samples where used for long term oxidation having similar dimensions to as received samples.

3. Samples where ground again to 600 -grit in order to remove surface scratches and imperfections left by the sectioning of the samples.

4. Dimension of the samples where measured using a micrometer in order to calculate surface area exposed in the oxidation experiments.

5. Samples underwent a 10-15 minute ultrasonic bath in ethanol to remove any impurities and organic debris on the surface of alloy.

6. Ceramic crucibles made of Leco $528 \mathrm{HP}$ where baked in box furnaces at $300^{\circ} \mathrm{C}$ for 24 hours, in order dehydrate and burn out any organic impurities.

7. All samples were weighed before and after oxidation experiments using a Sartorius analytical balance (model MC210S) with precision up to six decimal places.

\subsection{Oxidation Experiments}

The oxidation behavior of both alloys was studied in stagnant air in a temperature range from 300 to $700^{\circ} \mathrm{C}$ in a box furnace (Linderberg/Blue M model 1100) equipped with a computer controlled temperature device. Actual temperature of the samples was also measured by inserting 
a thermocouple into the furnace and touching the crucible containing the sample. The heating rate was set to $10^{\circ} \mathrm{C} /$ minute for all experiments. Isothermal short term oxidation (STO) for 24 hours and cyclic long term oxidation (LTO, 7 x 24 hour cycles) for 168 hours experiments were performed on the as cast alloys. All samples were furnace cooled to room temperature after each oxidation treatment. The samples were weighed before and after heating to determine the weight gain per unit area as a function of either temperature for STO or time for LTO treatments.

\subsection{Sample Characterization}

After oxidation experiments, samples were kept in sealed glass vials to avoid contamination before characterization. Sample characterization of the as-cast alloys and oxidized samples was performed via scanning electron microscopy (SEM), which includes energy dispersive spectroscopy (EDS), and back-scatter electron mode imaging; also x-ray diffraction (XRD) was used to identify crystal structures of the phases present in the as-cast alloy and oxides

formed after each experiment. Sample characterization was performed in facilities provided by the University of Texas at El Paso Metallurgical and Materials Engineering Department.

\subsubsection{Macrographs of Samples after Oxidation}

Using a standard digital camera, photographs were taken of selected samples after oxidation experiments in order to obtain a macroscopic view of the degradation of the samples. 


\subsubsection{Scanning Electron Microscopy, SEM}

As-cast and oxidized samples were mounted or encapsulated in epoxy resin and ground using a series of silicon carbide papers: 240, 400, 600, 800, 1000 and 1200 grit. A final polishing was performed with alumina slurries with particle sizes of $1 \mu \mathrm{m}, 0.5 \mu \mathrm{m}$ and $0.03 \mu \mathrm{m}$ on felt cloth. Samples were rinsed in water, and subsequently in ethyl alcohol before drying. A chemical etchant consisting of $10 \% \mathrm{HF}$ acid in distilled water ${ }^{[19]}$ was used to chemically attack the surface of the samples in order to improve the contrast of the different phases in the microstructure. Before SEM analysis all samples were sputter coated with gold using a SPI-Module sputter coater to prevent any charging effects. The microstructures were analyzed by scanning electron microscope (SEM), in secondary electron and backscatter electron imaging modes using Hitachi S-4800 (FESEM), and the chemical composition of the phases was determined by energy dispersive spectroscopy (EDS) using EDAX Inc. Genesis Spectra Version 5.21. Backscatter electron imaging mode provides image contrast as a function of elemental composition, and energy dispersive spectroscopy provides a qualitative analysis of elemental concentration. EDS analysis was performed in both the metal surface and in the oxide scale; at least 5 readings were taken of different microstructural features to obtain a better understanding of concentration of elements in different phases. Readings were performed with an elapsed time of 50 seconds. Periodical calibration of EDAX detector was performed using very pure aluminum and copper samples following calibration procedures provided by the SEM machine manufacturer in the user's manual. EDS analysis was correlated with the use of XRD technique, and Pandat 7.1 Thermodynamical Phase Diagram Calculation software. The parameter used for SEM, BSE, and EDS were $20 \mathrm{kV}$ accelerating voltage, with a probe current of $20 \mu \mathrm{A}$ and a working distance 
ranging from 8.0 to 15.0 millimeters.

\subsubsection{X-Ray Diffraction, XRD}

Moreover, X-ray diffraction (XRD) was used to identify the phases using a Scintag Inc. XDS diffractometer with a monochromatic $\mathrm{CuK \alpha}(\lambda=1.540562$ Angstroms) radiation. The parameters used for XRD analysis are the following:

- Generator voltage: $45 \mathrm{kV}$

- Generator current: $45 \mathrm{~mA}$

- Step size: $0.05^{\circ}$

- Time at each step: 0.5 seconds

- $2 \theta$ angle range: 20 to $90^{\circ}$

- Tube divergence and scatter slits: 2 and $4 \mathrm{~mm}$, respectively

- Detector convergence and receiving slits: 0.1 and $1 \mathrm{~mm}$, respectively

Previously stated polishing techniques were used on the as-cast samples to remove any surface impurities before XRD. On the other hand, oxide products were pulverized in a glass mortar until fine powders were obtained and the powder was adhered to a glass slide by using petroleum jelly before XRD analysis. Identification of the phases, or oxides was made by the Scintag and Radian Ltd. Powder Diffraction database version 1.06. 


\subsubsection{Phase Diagram Modeling}

Ternary phase diagram and fraction of phase calculations were produced with the help of Pandat ${ }^{\mathrm{TM}}$ version 7.1 software provided by CompuTherm LLC (Madison, WI). This program can produce isothermal sections for a variety of alloy systems as a function of elemental composition. Prediction of different stable phases as a function of composition can be envisaged in a range of temperatures. The software uses experimental and theoretical thermodynamic data to predict phase stability, crystal structure, and other parameters as a function of alloying degree and temperature.

\subsubsection{Hardness Testing}

In order to obtain some indication of mechanical properties of the samples, Rockwell hardness measurements were taken on as-cast and oxidized alloys. Rockwell hardness measurements were performed using an Instron Wilson Rockwell Series 2000T harness machine with software Version 2. An ASTM International E 18-07 standard test method for Rockwell Hardness of Metallic Materials was followed. ${ }^{[41]}$ The parameters used in the Rockwell scale A hardness measurements were $10 \mathrm{~kg}$ initial load, and $60 \mathrm{~kg}$ final load using a diamond indenter. 


\section{CHAPTER 4}

\section{RESULTS AND DISCUSSION}

\subsection{As-Cast Metal Microstructures}

\subsubsection{Phase Diagram Modeling and SEM images}

Isothermal sections of the ternary phase diagram of the $\mathrm{Zr}-\mathrm{Nb}$-Ti system as a function of composition in atomic percent were produced for different temperatures. Figure 6 shows the isothermal sections at $25,300,400,500,600$, and $700^{\circ} \mathrm{C}$ from the $\mathrm{Zr}-\mathrm{Nb}$ - $\mathrm{Ti}$ ternary phase diagrams as calculated by the Pandat ${ }^{\mathrm{TM}} \cdot{ }^{[1,2]}$ The two selected alloys of this study fall into the area of two phase field at room temperature. The expected phases are $\alpha-\mathrm{Zr}-\mathrm{HCP}$ and $\beta-\mathrm{Nb}-\mathrm{BCC}$ solid solutions. (HCP: Hexagonal Close Packed, BCC: Body Centered Cubic) 

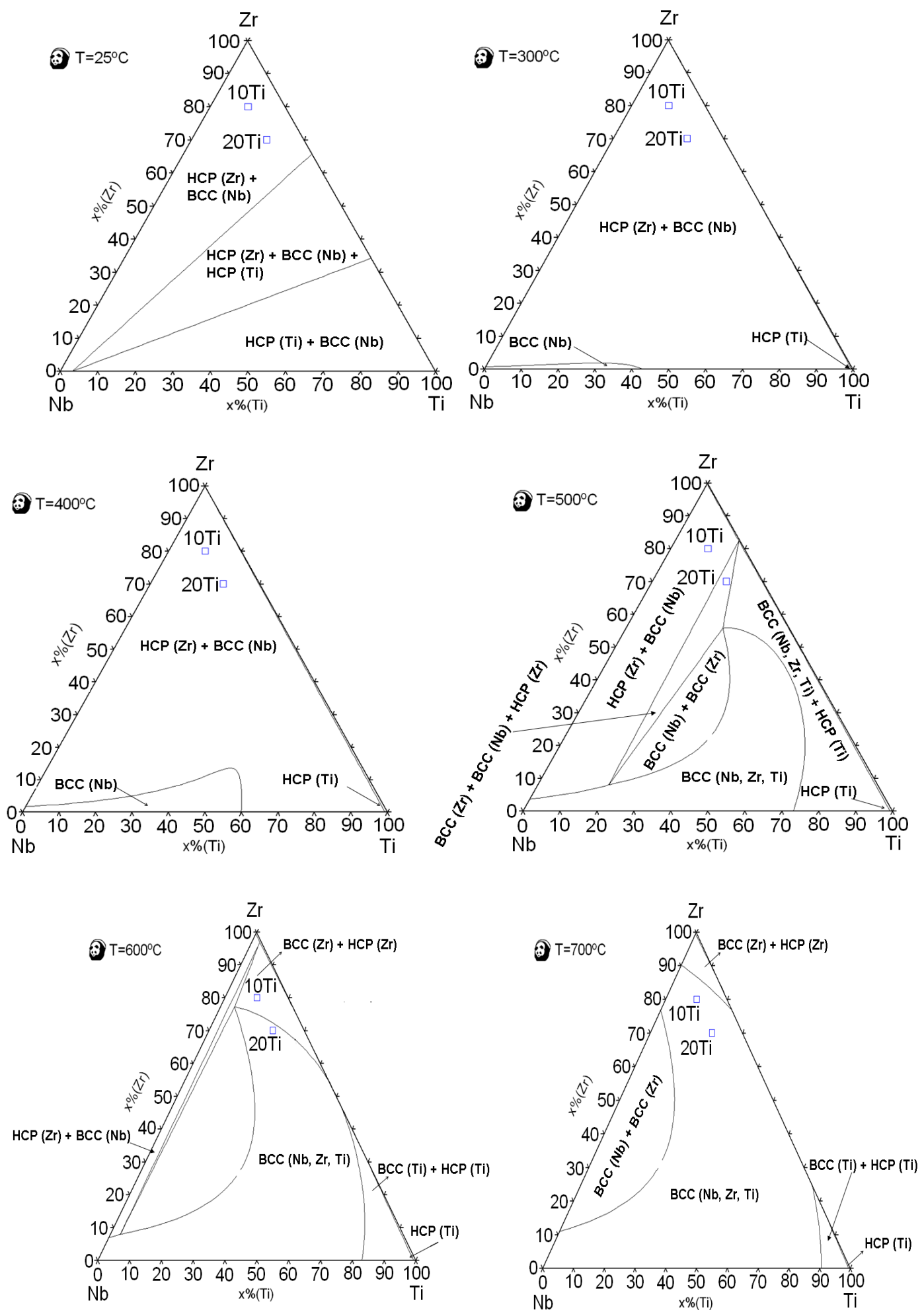

Figure 6. Isothermal sections of the Zr-Ti-Nb system calculated with Pandat ${ }^{\mathrm{TM}}{ }^{[1,2]}$. 

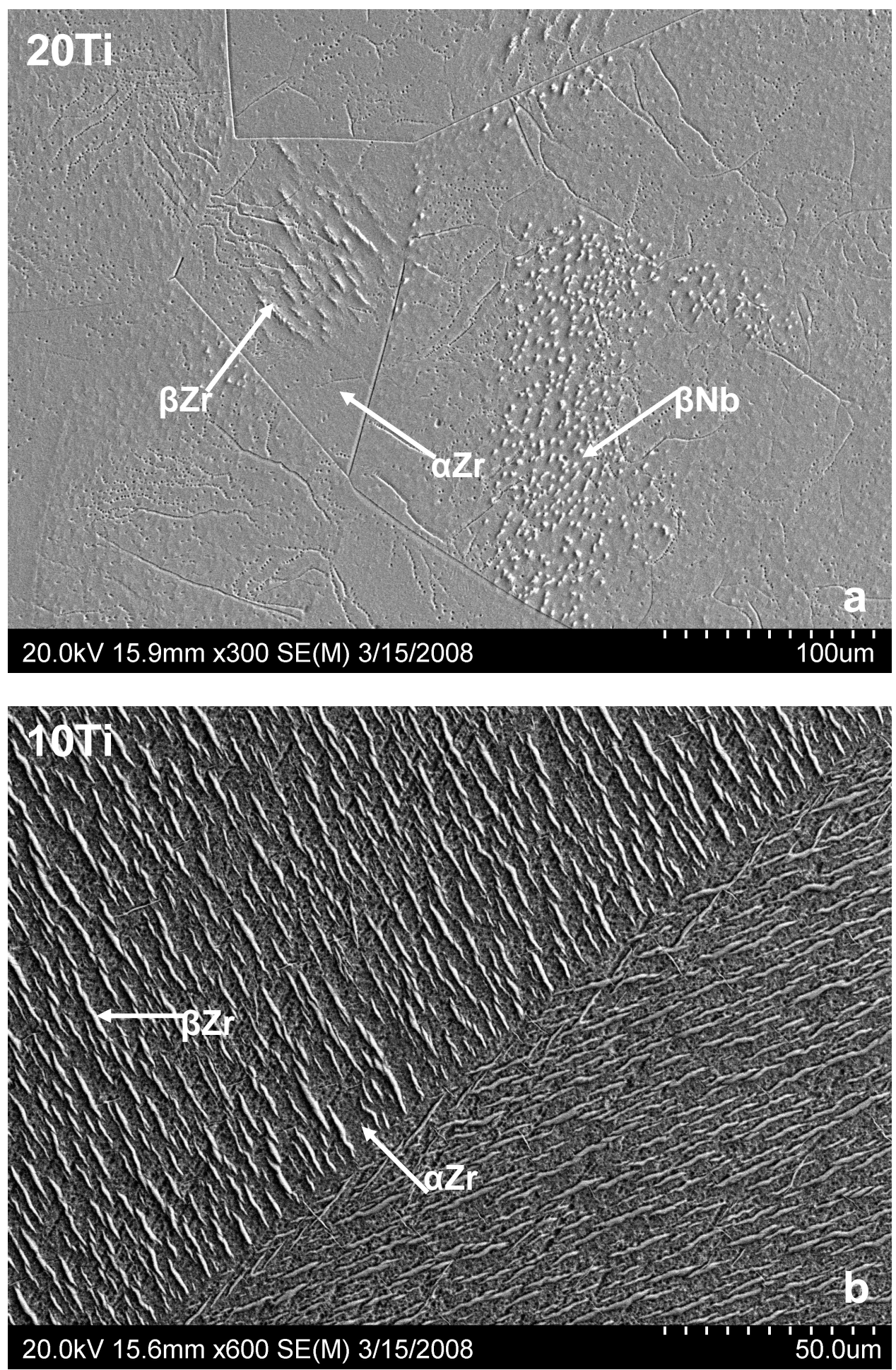

Figure 7. As cast microstructure of the (a) 20Ti and (b) 10Ti alloys. 
Figure 7 shows the microstructures of the alloys in the as cast condition. The matrices in both cases appear to be $\alpha-\mathrm{Zr}$ solid solution. However, $\beta$-Zr-BCC laths are also present in both alloys (contrary to the isotherms shown in Figure 6). The 20Ti alloy also contains fine rounded $\beta-\mathrm{Nb}$ particles.

\subsubsection{X-Ray Diffraction, XRD}

The XRD patterns obtained for the as-cast alloys are shown in Figure 8. Characteristic XRD peaks were matched to different phases with different crystal structures and lattice parameters using a diffraction powder database. The phases observed using scanning electron microscopy are confirmed with the XRD patterns obtained of the as-cast alloys. The 10Ti XRD shows the presence of $\alpha-\mathrm{Zr}(\mathrm{HCP})$ and $\beta-\mathrm{Zr}$ (BCC) which was previously observed in the SEM micrographs. Non-equilibrium microstructures can be present opposed to the expected thermodynamically stable phases due to fast cooling rates that do not permit the complete transformation of equilibrium structures in metals. On the other hand, the 20Ti XRD shows peaks of $\alpha-\mathrm{Zr}$ (HCP), along with $\beta-\mathrm{Nb}$ (BCC); no $\beta-\mathrm{Zr}$ (BCC) peaks were observed in this pattern, even though a small quantity of laths was observed in the SEM micrographs. 

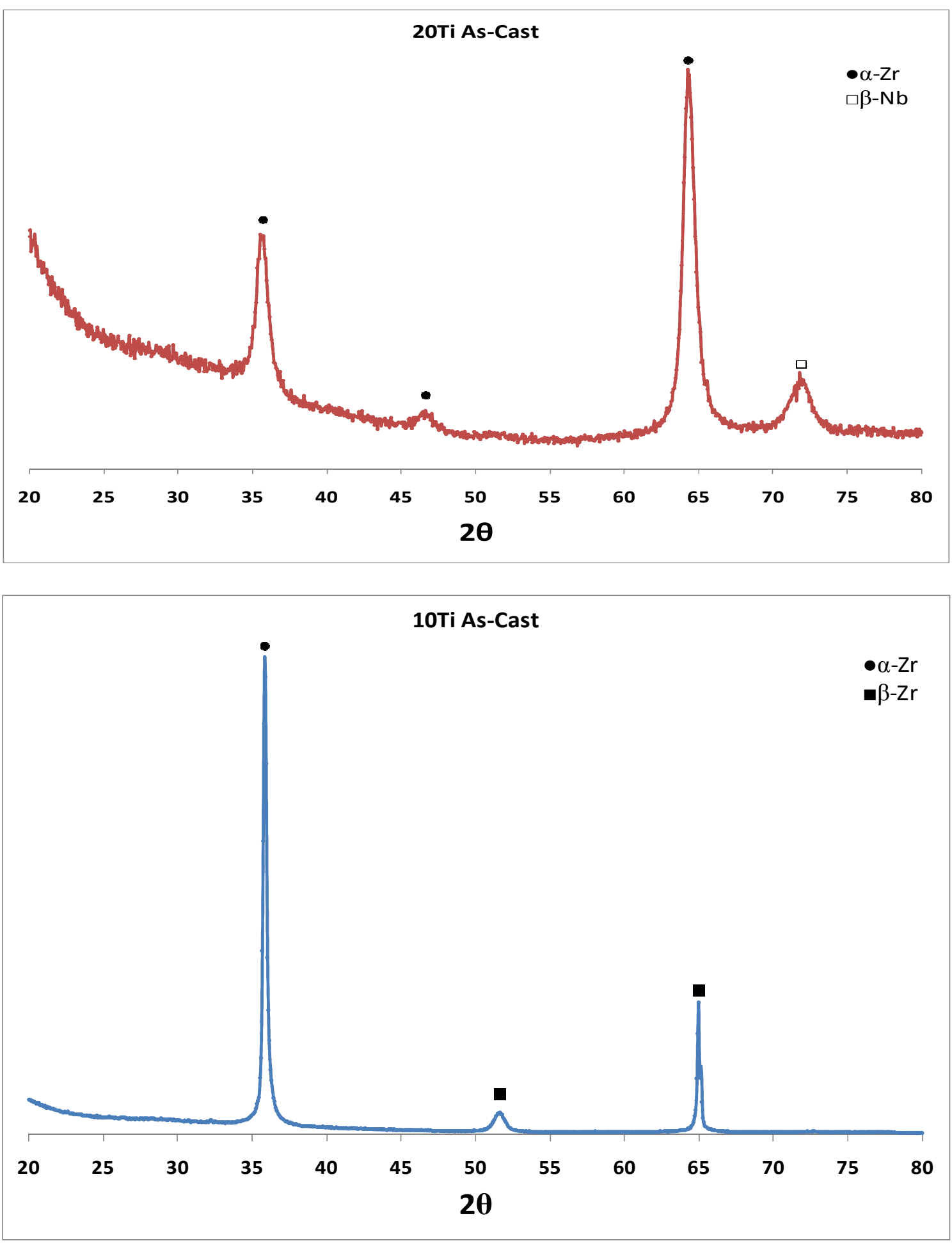

Figure 8. XRD patterns of as-cast alloys. 


\subsection{Short Term Oxidation Curves}

Figure 9 shows the weight gain per unit area (W) as a function of oxidation temperature from 300 to $700^{\circ} \mathrm{C}$ under STO conditions. This figure includes the anticipated phases in the two alloys based on the oxidation temperatures using the isotherms in Figure 6. Obviously this can allow the determination of the relationship between the phases and oxidation behavior directly. The low $\mathrm{W}$ values up to $500^{\circ} \mathrm{C}$ for both alloys are indicative of the presence of $\beta-\mathrm{Nb}$ and $\alpha-\mathrm{Zr}$ phases. More detailed examination of the isotherms in this system indicates that two phase region exists up to $490^{\circ} \mathrm{C}$ for $20 \mathrm{Ti}$ and up to $545^{\circ} \mathrm{C}$ for $10 \mathrm{Ti}$ alloy. This means that the introduction of $\beta-\mathrm{Zr}$ (BCC) appears at $490^{\circ} \mathrm{C}$ and $545^{\circ} \mathrm{C}$ for 20 and $10 \mathrm{Ti}$ alloys respectively. However, the alloys continue to show good oxidation resistance because of the existence of the $\beta-\mathrm{Nb}$ phase even in the 3 phase field. The sharp increase in the $\mathrm{W}$ values for both alloys appears to be associated with the disappearance of $\beta-\mathrm{Nb}$. It also appears that the two alloys go through similar phase transformations but the transformation temperatures are raised for the 10Ti alloy. The following reaction shows the phase transformation according to the isotherms of Figure 6 (temperature increases from left to right):

$$
\beta \mathrm{Nb}+\alpha \mathrm{Zr} \rightarrow \beta \mathrm{Nb}+\alpha \mathrm{Zr}+\beta \mathrm{Zr} \rightarrow \alpha \mathrm{Zr}+\beta \mathrm{Zr} \rightarrow \beta \mathrm{Zr}
$$

$\beta-\mathrm{Nb}$ phase then should be interpreted as the microconstituent present in this system which provides the oxidation resistance. It must be noted that the 3 phase region, $\alpha-\mathrm{Zr}, \beta-\mathrm{Nb}, \beta-$ $\mathrm{Zr}$, are stable in a small temperature region consisting of only $20^{\circ} \mathrm{C}$ in both alloys. 
Microstructures transform to two phase with $\mathrm{Nb}$ going to solid solutions with $\mathrm{BCC}$ and $\mathrm{HCP}$ forms of $\mathrm{Zr}$ when temperatures are raised above the three phase regions. It has been observed that the alloys turn into complete powder once $\alpha-\mathrm{Zr}$ disappears from microstructures in these alloys leaving behind $\beta-\mathrm{Zr}$ as a single phase microconstituent. Another interesting feature of Figure 9 includes the demonstration of improved oxidation resistance by the Ti addition up to a temperature of nearly $500^{\circ} \mathrm{C}$ even though the differences between the $\mathrm{W}$ values for the two alloys may be very insignificant. It should be noted the 10Ti alloy continues the linear oxidation until nearly $565^{\circ} \mathrm{C}$. 

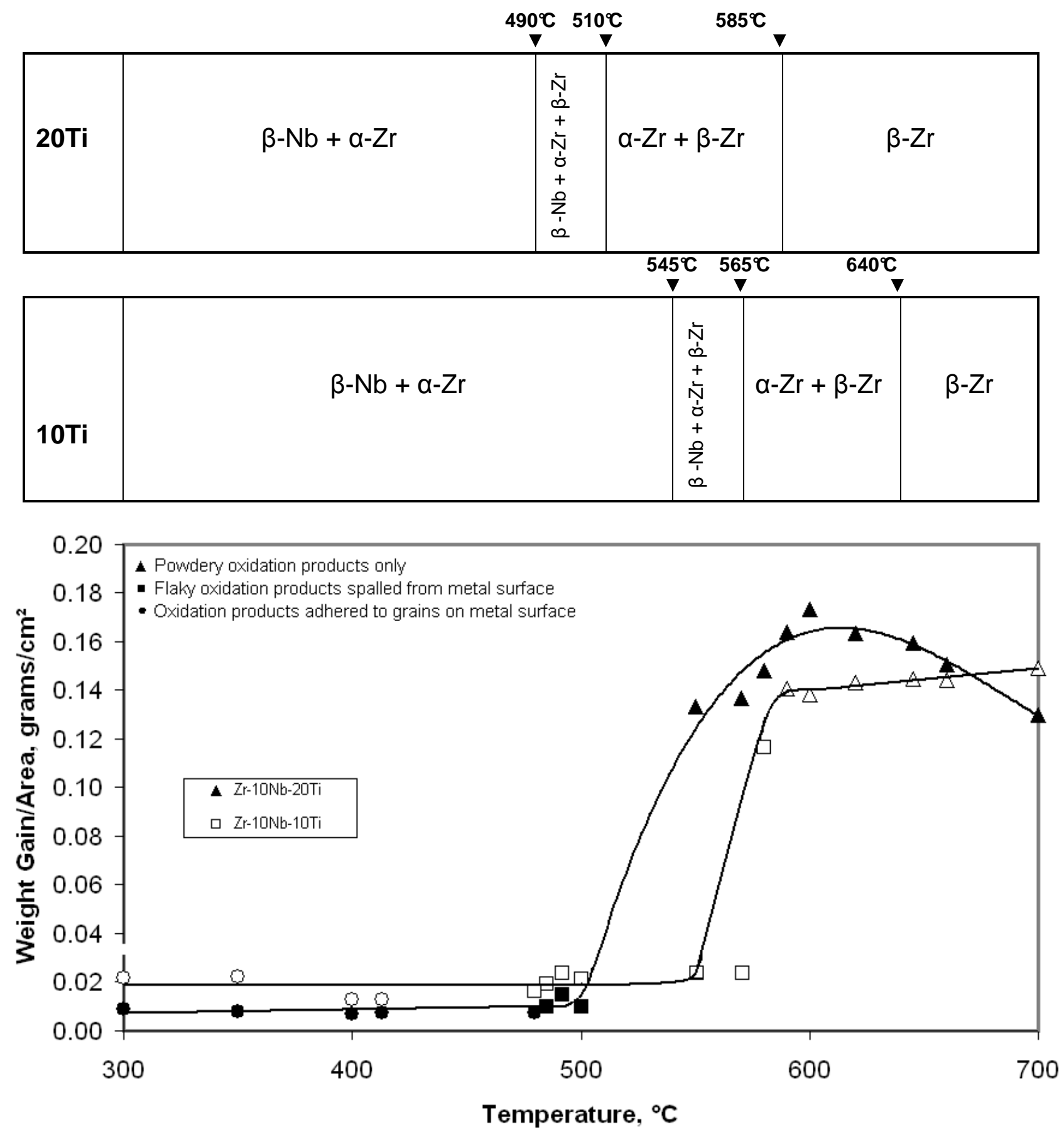

Figure 9. Short term oxidation (STO) graph showing weight change per unit area at different temperatures for 10Ti and 20Ti alloys. 


\subsubsection{After STO Macrographs}

Low magnification photographs were taken of each sample after STO experiments (Fig. 10-15) from these macrographs we can get insight on the degradation of the sample upon reaction with air at different temperatures. Micrographs for 20Ti and 10Ti alloys after STO experiments are shown in the range of temperatures from 400 to $700^{\circ} \mathrm{C}$. It is evident that degradation of the samples is based on the formation of oxidation products, and flaking increases as a function of temperature in both samples. Initial preferential oxidation of certain microstructure and/or grains can be observed due to the formation of black oxides on the surface of the metallic samples features. These dark oxides have been characterized by other studies, as initial zirconium-rich suboxides with high density of oxygen vacancies. These oxides have a pseudo crystalline structure, due to the presence of many point defects in the lattice. At lower temperatures, $400^{\circ} \mathrm{C} 20 \& 10 \mathrm{Ti}$ samples have similar degree of degradation (Figure 10, a \& b), but the difference in degradation is more evident after $\mathrm{STO}$ at $500^{\circ} \mathrm{C}$ (Figure 11, a, \& b) where we can clearly see that the alloy with higher titanium content appears to have a better oxidation resistance. Some spalled oxides can be observed in the $10 \mathrm{Ti}$ alloy macrograph after $500^{\circ} \mathrm{C} \mathrm{STO}$. Furthermore, photographs of the samples after $\mathrm{STO}$ at $550^{\circ} \mathrm{C}$ (Figure 12 , a \& b), show an increase in the degradation of the 20Ti alloy relative to the 10Ti alloy; the 20Ti alloy has been completely oxidized after 24 hours, leaving flake and powder white oxide products, while the 10Ti alloy did not any undergo catastrophic oxidation; it conserves its cubic shape with no severe formation or decohesion of oxidation products. Moreover, oxides like zirconia, titania, and niobium pentoxide are well known for their white colored solid appearance; the presence of these oxides also has been confirmed with XRD. Furthermore, macrographs of 10Ti samples 
after STO experiments at 570 and $580^{\circ} \mathrm{C}$ (Figure 13, a \& b), respectively, are presented in order to track the changes in the samples appearance after exposure. We can observe that the degradation of 10Ti alloy samples increases as a function of temperature, but a solid metal piece is still present at the end of the test giving us insight on the extent of oxidation of the samples. Furthermore, experiments performed at these intermediate temperatures, $500^{\circ}<\mathrm{T}<600^{\circ} \mathrm{C}$ (Figure 11-14), show that 20Ti sample undergoes a catastrophic oxidation while the 10Ti sample oxidizes to a smaller extent showing a more passive oxidation, and more gradual degradation. The previous results at intermediate temperatures are closely related to the microstructural and phase changes taking place in the microstructure of the alloy as a function of temperature. Furthermore, after the $600^{\circ} \mathrm{C}$ (Figure 14) isothermal 24 -hour experiments the both alloys have completely oxidized showing scale, chunks and powder products. Finally, at $700^{\circ} \mathrm{C}$ (Figure 15, a \& b) both metallic samples have converted into powder oxidation products after STO experiments.

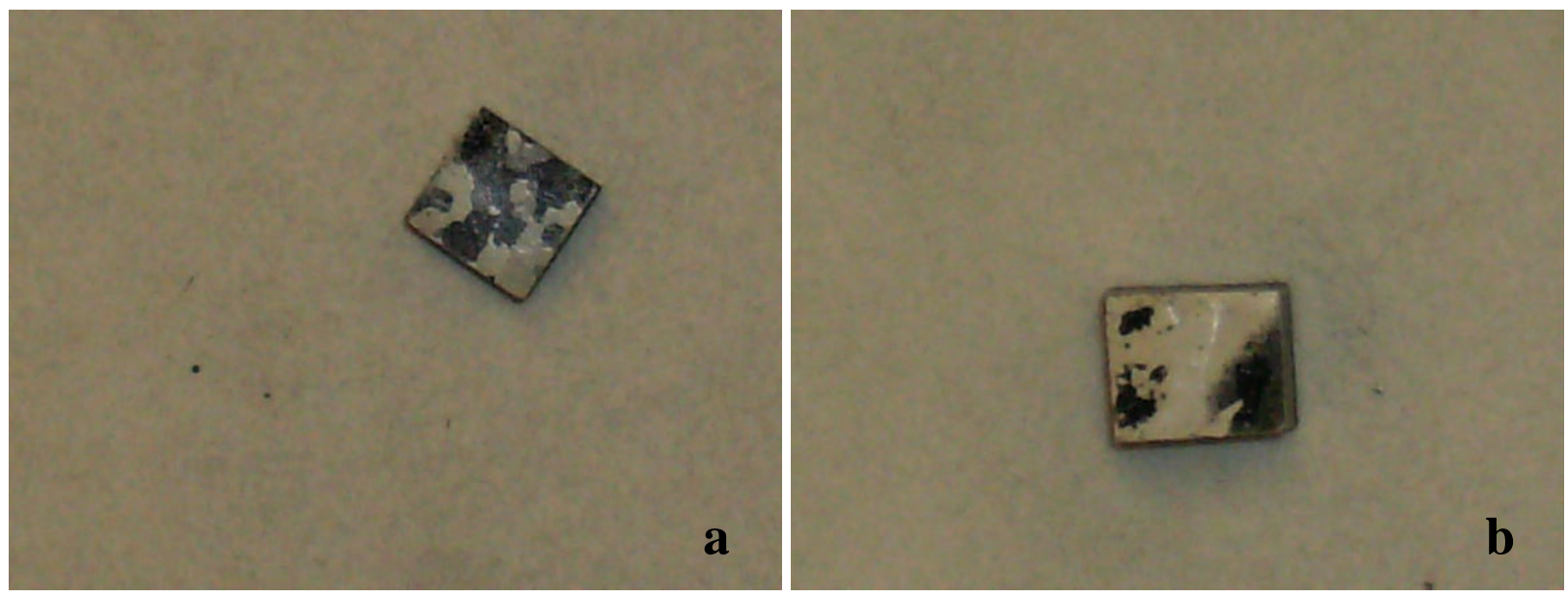

Figure 10. Macrograph of 20Ti (a) \& 10Ti (b) alloys after STO at $400^{\circ} \mathrm{C}$. 


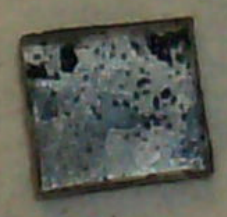

a

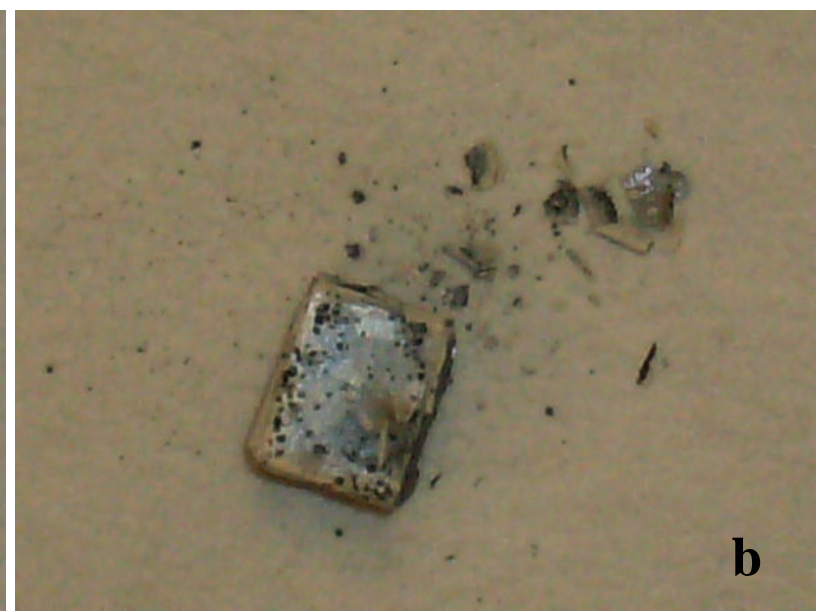

Figure 11. Macrograph of 20Ti (a) \& 10Ti (b) alloys after STO at 500ㄷ.

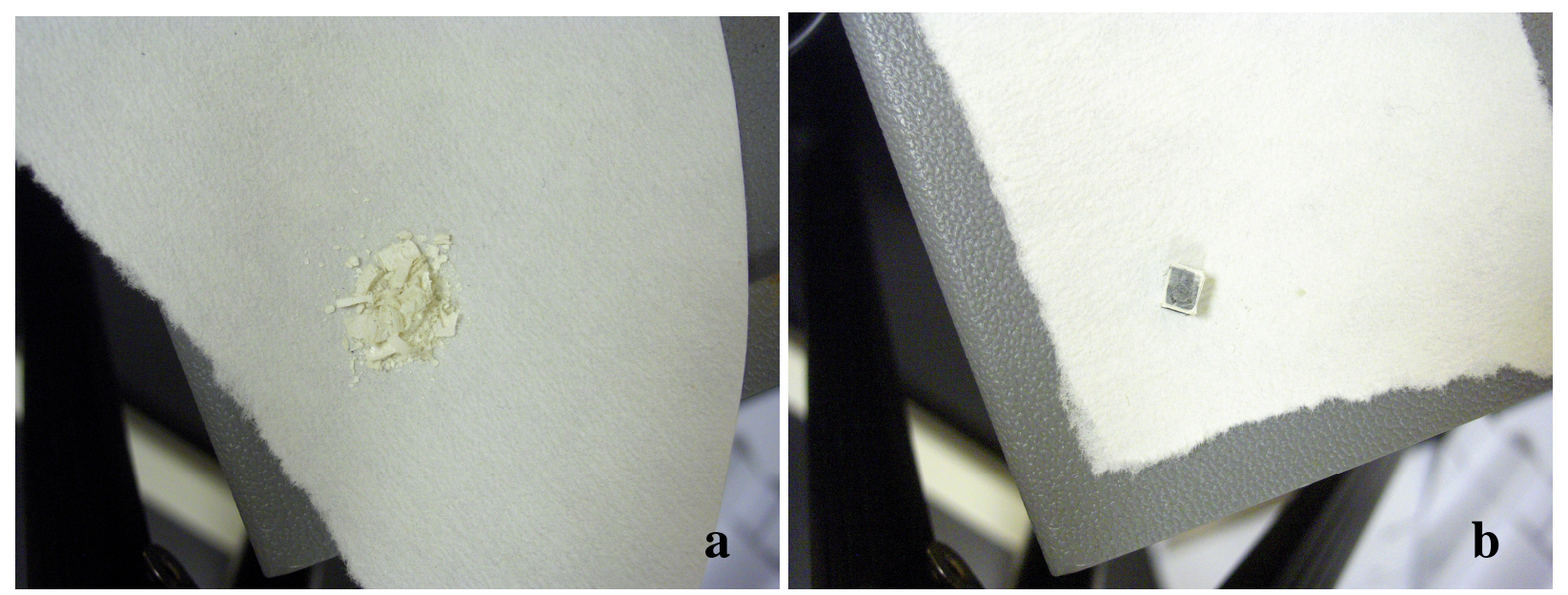

Figure 12. Macrograph of 20Ti (a) \& $10 \mathrm{Ti}$ (b) alloys after STO at $550^{\circ} \mathrm{C}$.

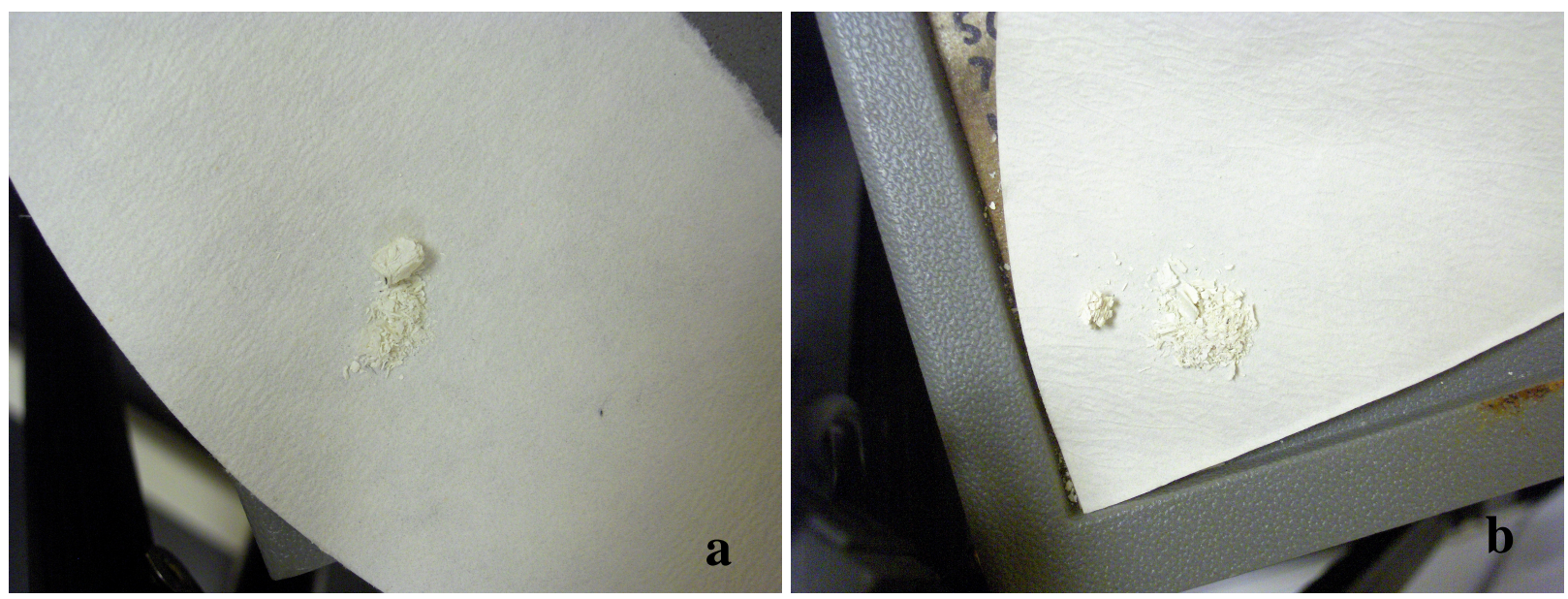

Figure 13. Macrograph of 10Ti alloy after STO at 570 (a) and $580^{\circ} \mathrm{C}$ (b). 

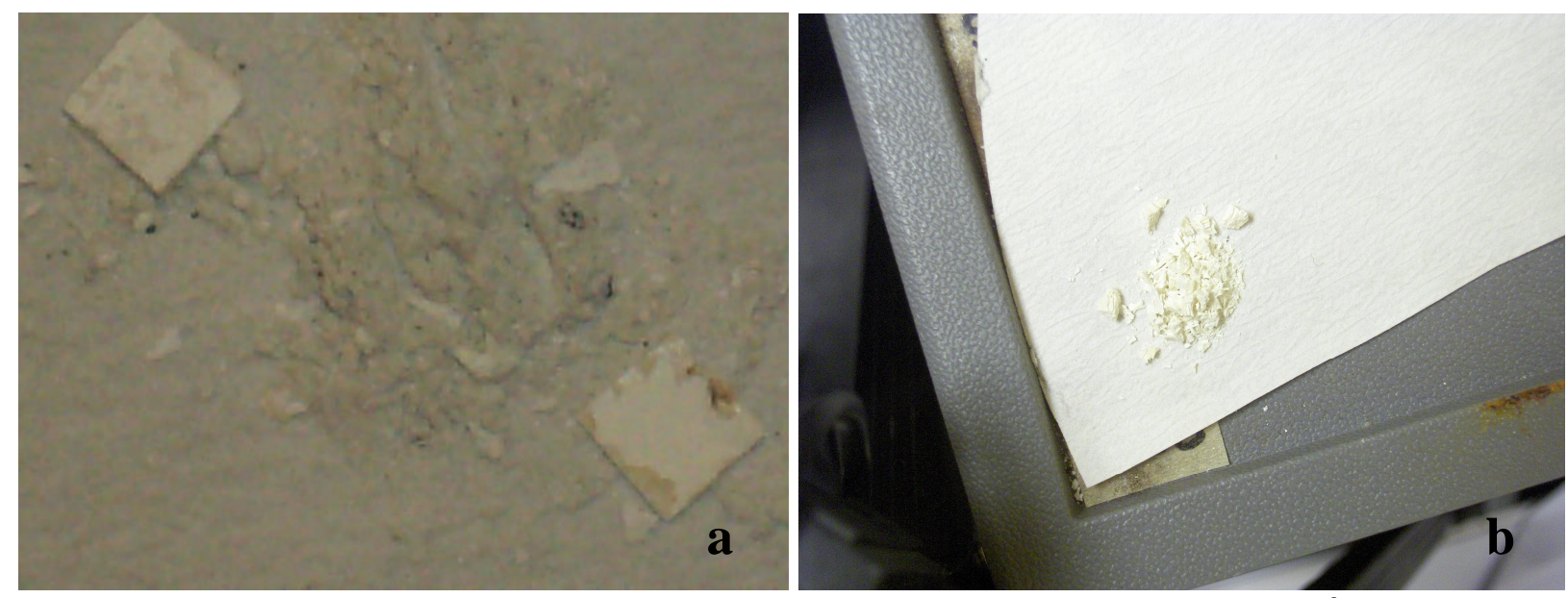

Figure 14. Macrograph of 20Ti (a) \& 10Ti (b) alloys after STO at $600^{\circ} \mathrm{C}$.
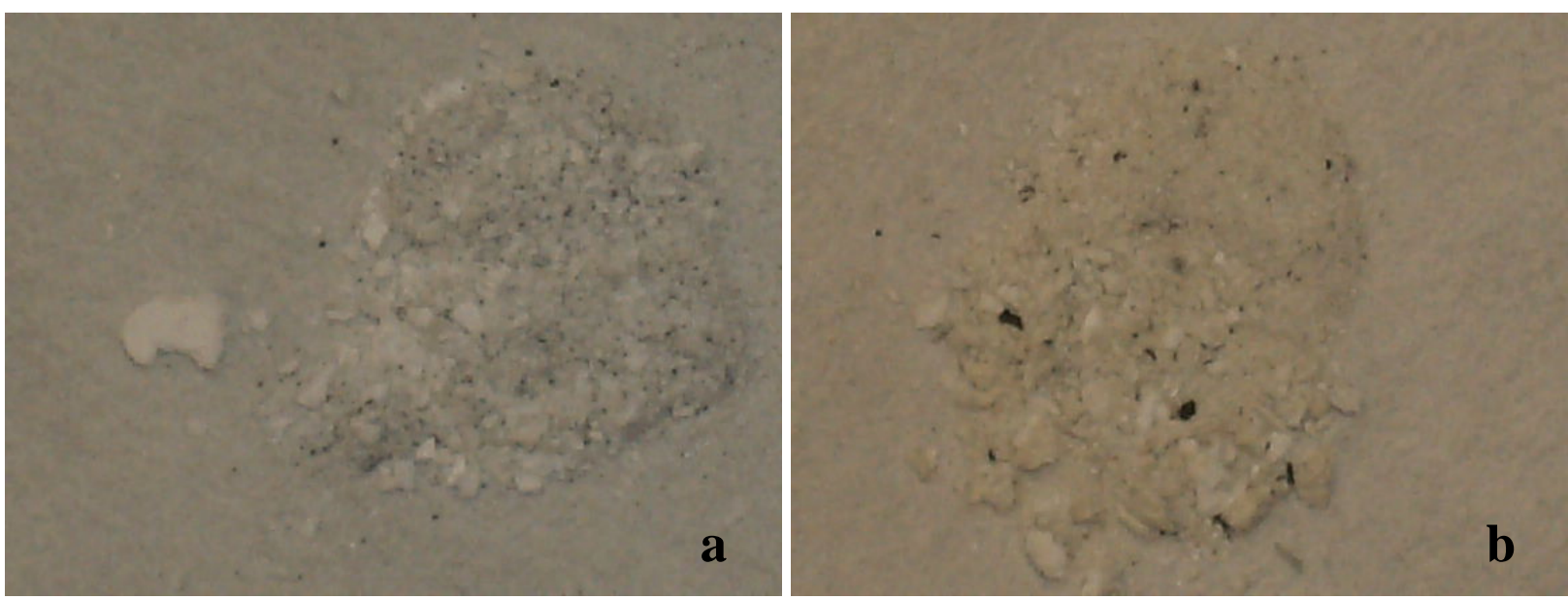

Figure 15. Macrograph of 20Ti (a) \& 10Ti (b) alloys after STO at $700^{\circ} \mathrm{C}$.

\subsubsection{Microstructures}

Figure 16 shows the microstructures developed at $400^{\circ} \mathrm{C}$ for both alloys. The dispersion of rounded $\beta \mathrm{Nb}$ particles in $\alpha \mathrm{Zr}$ matrix is quite evident from this figure. It confirms the 2 phase microstructure prediction from the isotherms at $400^{\circ} \mathrm{C}$. $20 \mathrm{Ti}$ alloy shows a three phase microstructure at $500^{\circ} \mathrm{C}$ as shown in Figure 17 by the inclusions of the $\beta \mathrm{Zr}$ laths. On the other hand the $10 \mathrm{Ti}$ alloy continues to possess the two phase microstructure at $500^{\circ} \mathrm{C}$. It agrees well with the isotherm at $500^{\circ} \mathrm{C}$ shown in Figure 6. The development of a three phase microstructure 
at $550^{\circ} \mathrm{C}$ in $10 \mathrm{Ti}$ alloy is shown in Figure 18 . This microstructure is very similar to that shown for the 3 phase microstructure of $20 \mathrm{Ti}$ alloy at $500^{\circ} \mathrm{C}$ in Figure 17 . The peculiar orientation of the $\beta \mathrm{Zr}$ laths it is traditionally termed a Widmanstätten pattern, and this is distinguished due its defined orientation in the octahedrites; previous studies have also observed the orientation of $\beta \mathrm{Zr}$ grains in this pattern. ${ }^{[29]} \mathrm{A}$ two phase microstructure consisting of $\alpha \mathrm{Zr}$ matrix and $\beta \mathrm{Zr}$ laths is shown in Figure 19 for $20 \mathrm{Ti}$ alloy at $562^{\circ} \mathrm{C}$ and $10 \mathrm{Ti}$ alloy at $610^{\circ} \mathrm{C}$. We can clearly see that these laths intersect themselves in specific crystallographic directions; change in misorientation angle depends on how the octahedron is cut, or in other words, depends on the grain orientation relative to the polished surface of the metal. This microstructure was obtained by heating the alloys for 2 hours at the indicated temperatures. Thus it appears that the microstructures evolved in this study conform well to the isotherms calculated by using the Pandat ${ }^{\mathrm{TM}}$ software. ${ }^{[2]}$ 

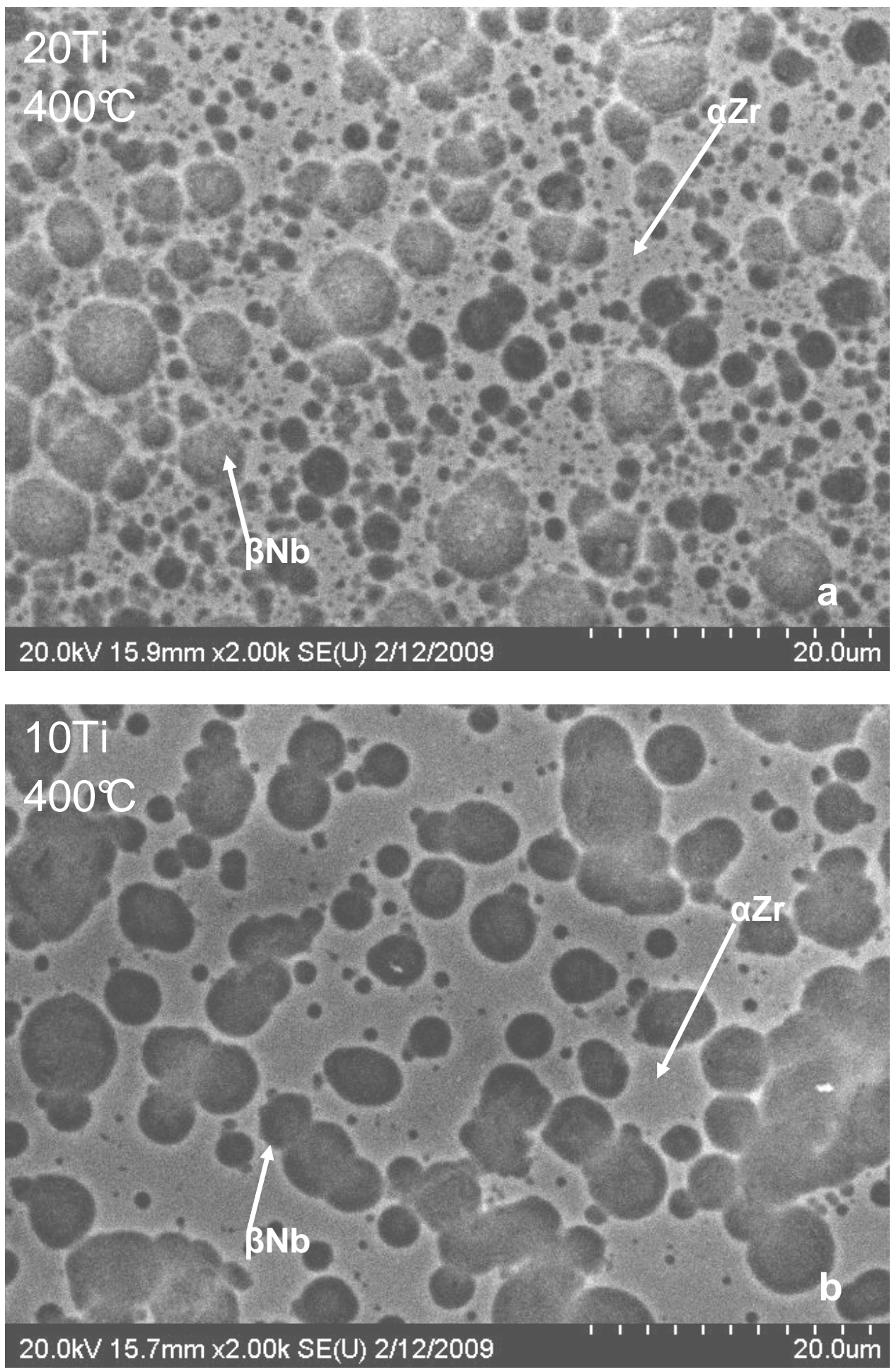

Figure 16. Microstructures of (a) $20 \mathrm{Ti}$ and (b) $10 \mathrm{Ti}$ alloys after STO treatment at $400^{\circ} \mathrm{C}$. 

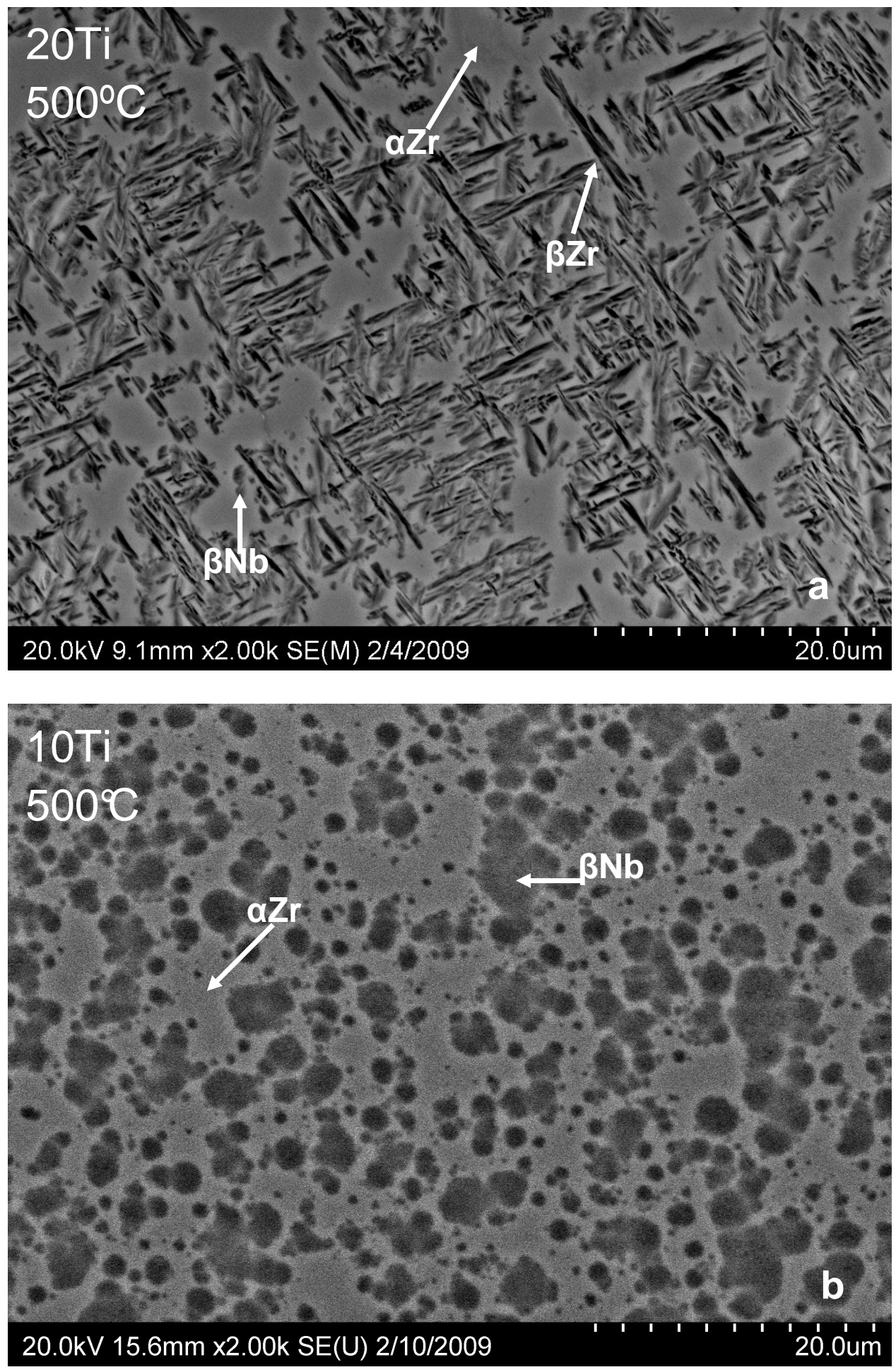

Figure 17. Microstructures of (a) $20 \mathrm{Ti}$ and (b) $10 \mathrm{Ti}$ alloys after STO treatment at $500^{\circ} \mathrm{C}$. 


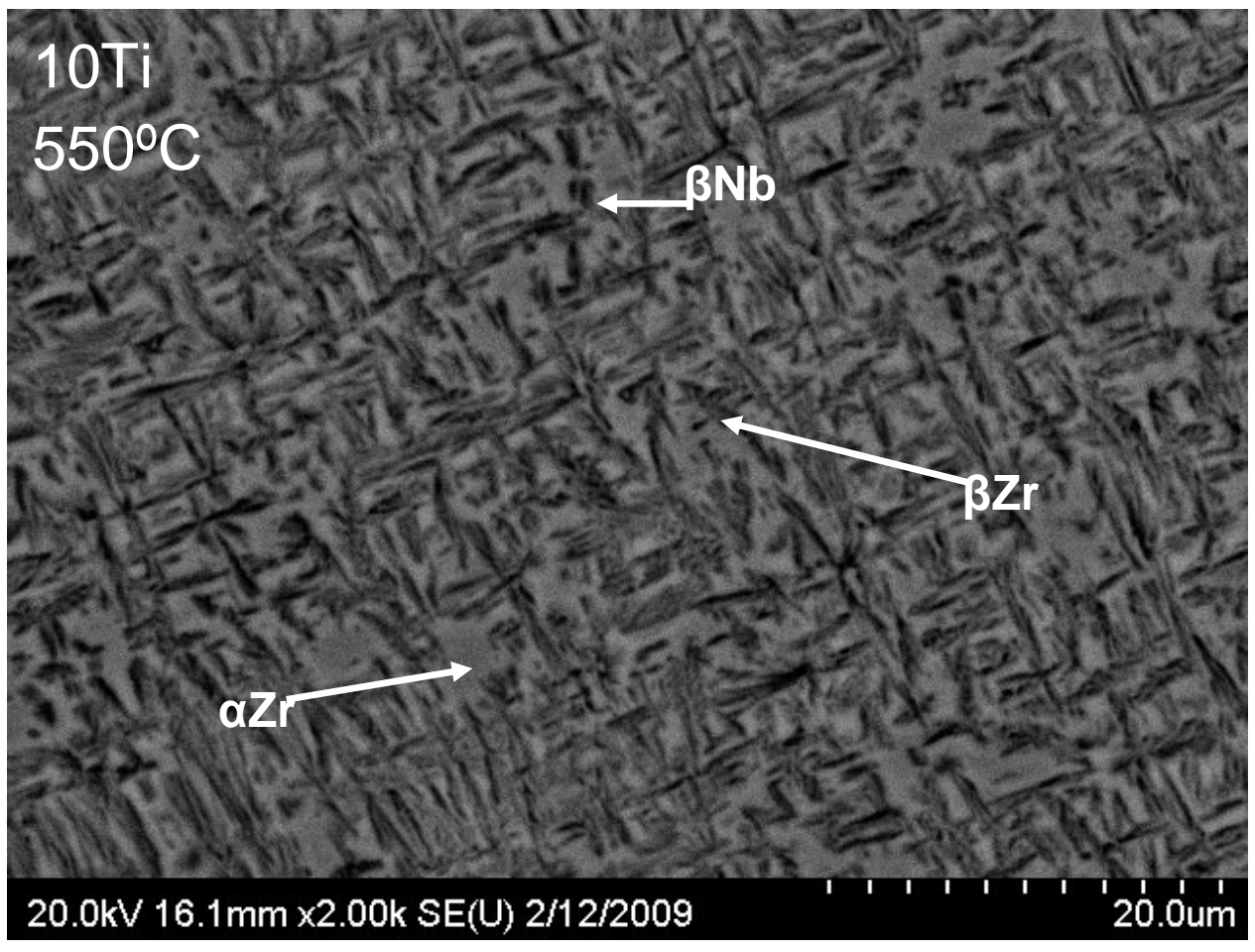

Figure 18. Microstructures of $10 \mathrm{Ti}$ alloy after STO treatment at $550^{\circ} \mathrm{C}$. 

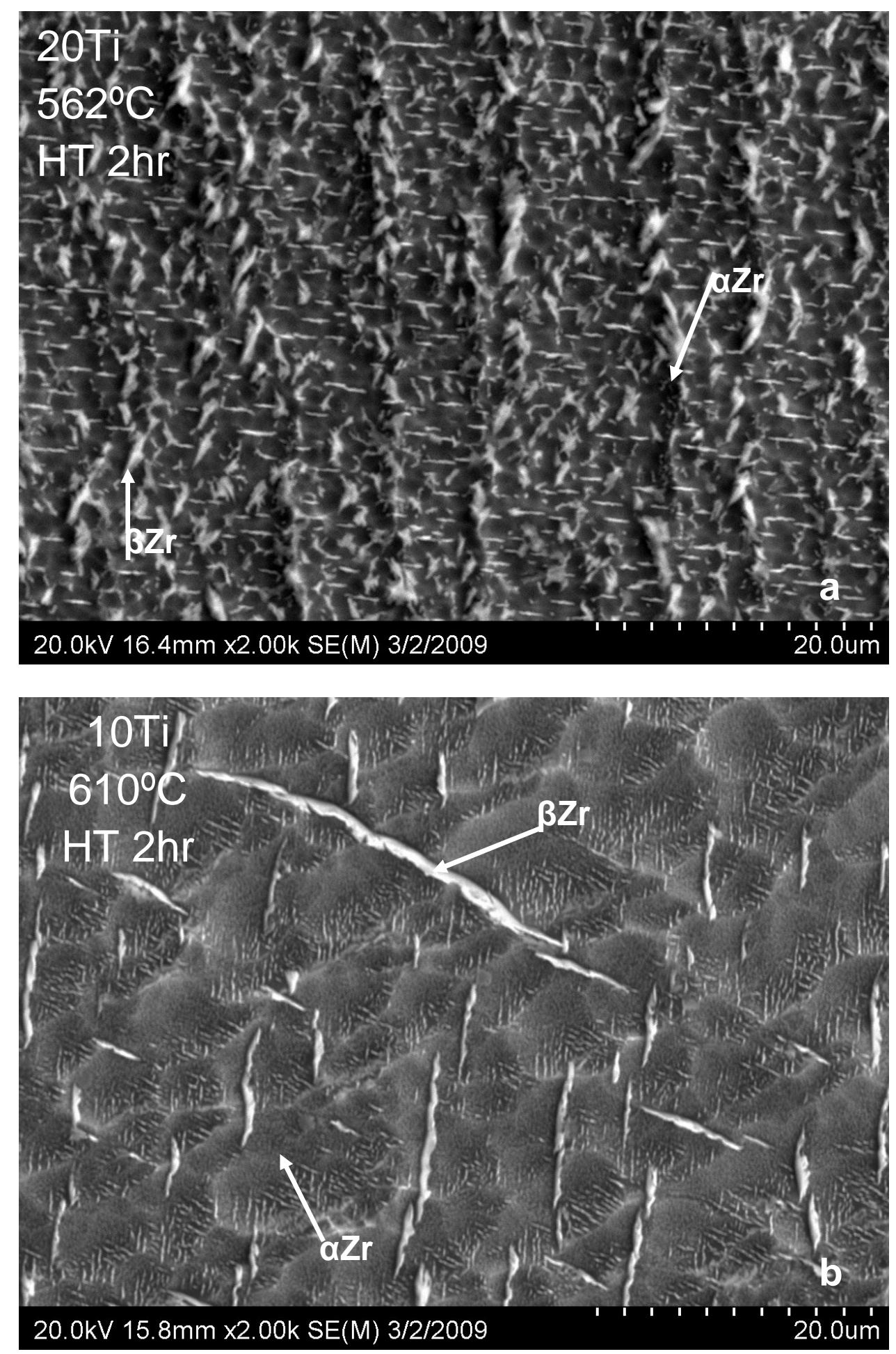

Figure 19. Microstructures of (a) $20 \mathrm{Ti}$ at $562^{\circ} \mathrm{C}$ and (b) $10 \mathrm{Ti}$ at $610^{\circ} \mathrm{C}$ after heating for 2 hours. 


\subsubsection{Backscatter Electron Imaging}

Backscatter electron imaging mode accentuates the contrast between different phases and separates them in different tones of gray that relate to different concentration of atom species in certain phases or microconstituents that are part of the microstructure. Figure 20 includes selected micrographs for the $20 \mathrm{Ti}$ and $10 \mathrm{Ti}$ alloy that show microstructure transformations taking place in the alloy due to phase changes. In these EBSD micrographs we can observe the formation of lath structure of $\beta \mathrm{Zr}$ by dissolution of preceding phases. This follows the thermodynamical phase transformations calculated by Pandat ${ }^{\mathrm{TM}}$ :

$$
\beta \mathrm{Nb}+\alpha \mathrm{Zr} \rightarrow \beta \mathrm{Nb}+\alpha \mathrm{Zr}+\beta \mathrm{Zr} \rightarrow \alpha \mathrm{Zr}+\beta \mathrm{Zr} \rightarrow \beta \mathrm{Zr}
$$



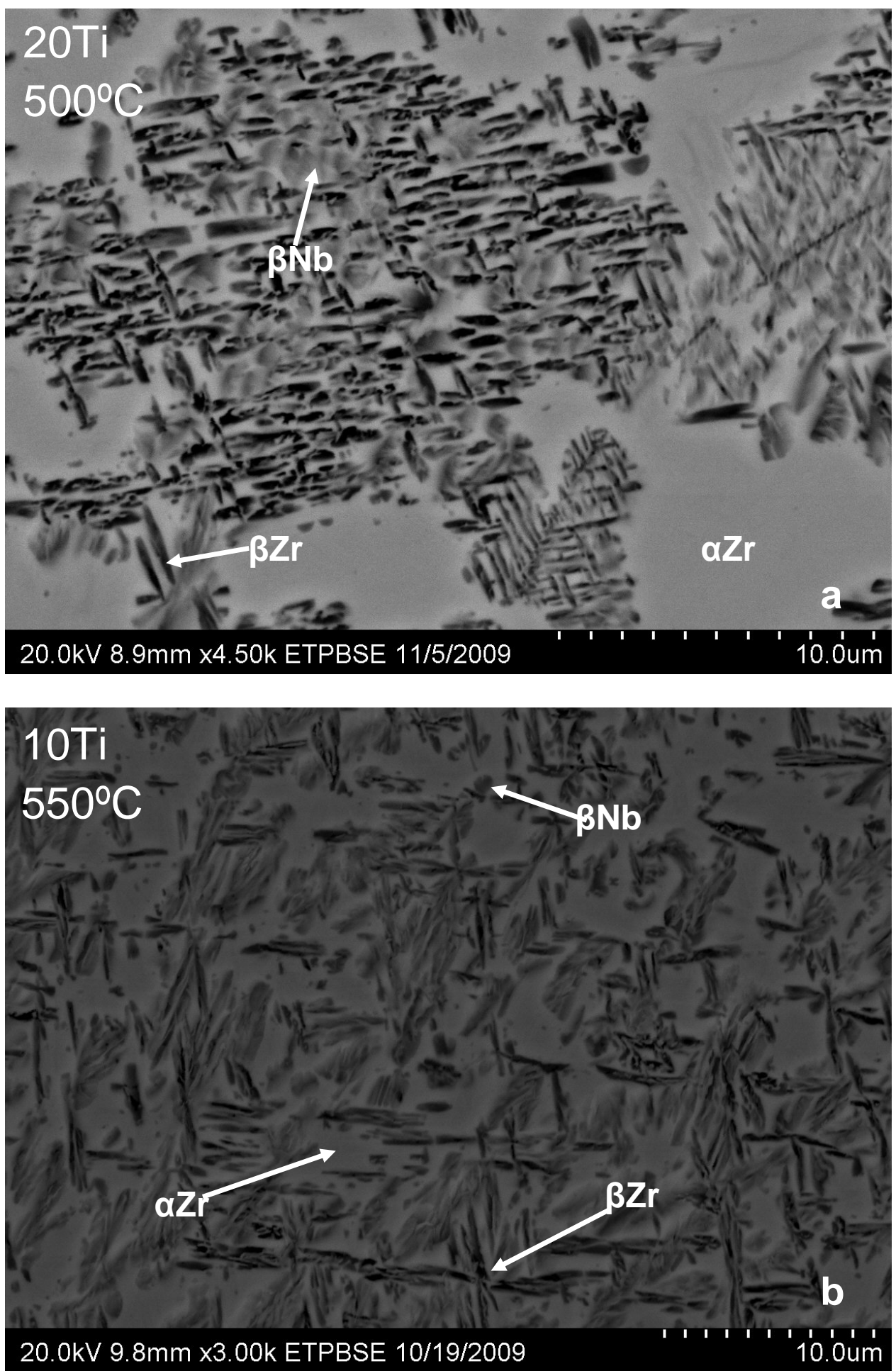

Figure 20. BSE micrographs of 20Ti (a) and 10Ti (b) alloys showing mictrostructural transformations after STO treatment at 500 and $550^{\circ} \mathrm{C}$, respectively. 


\subsubsection{X-ray Diffraction (XRD) Results}

Oxide identification after the oxidation treatments were restricted to only cases where significant amount of powder formed which would correspond to oxidized samples at 600 and $700^{\circ} \mathrm{C}$ only for both alloys. XRD patterns shown in Figure 21 indicate the presence of $\mathrm{TiO}_{2}$ (tetragonal), $\mathrm{ZrO}_{2}$ (monoclinic \& tetragonal) and $\mathrm{Nb}_{2} \mathrm{O}_{5}$ in both alloys at these temperatures. However, 10Ti alloy shows significant increase in the peak for monoclinic $\mathrm{ZrO}_{2}$ at 700 compared to the peaks at $600^{\circ} \mathrm{C}$. The results on the oxidation of the Ti-13Nb-13Zr, Ti- $15 \mathrm{Zr}-4 \mathrm{Nb}$ [21] alloys agree well with our results. Their XPS study on the oxide scale after 24 hours of oxidation in air at $750^{\circ} \mathrm{C}$ shows the presence of higher oxidation state, i.e., $\mathrm{Ti}^{4+}, \mathrm{Nb}^{5+}$, and $\mathrm{Zr}^{4+}$. Similar sets of oxide formation has been reported ${ }^{[20]}$ for $\mathrm{Zr}-10 \mathrm{Nb}$ alloys (obviously without $\mathrm{Ti}$ ) when oxidized in dry air between 973 and $1273 \mathrm{~K}$.

XRD patterns for samples below $500^{\circ} \mathrm{C}$ have not been reported in this study due to the absence of powder oxide formation. The samples either were oxidized to a negligible extent (marked as circles in Figure 9) or oxide formed (marked as square in Figure 9) was firmly attached to the metal surface. Powder formation is indicated by the triangular symbols in the STO graphs. 

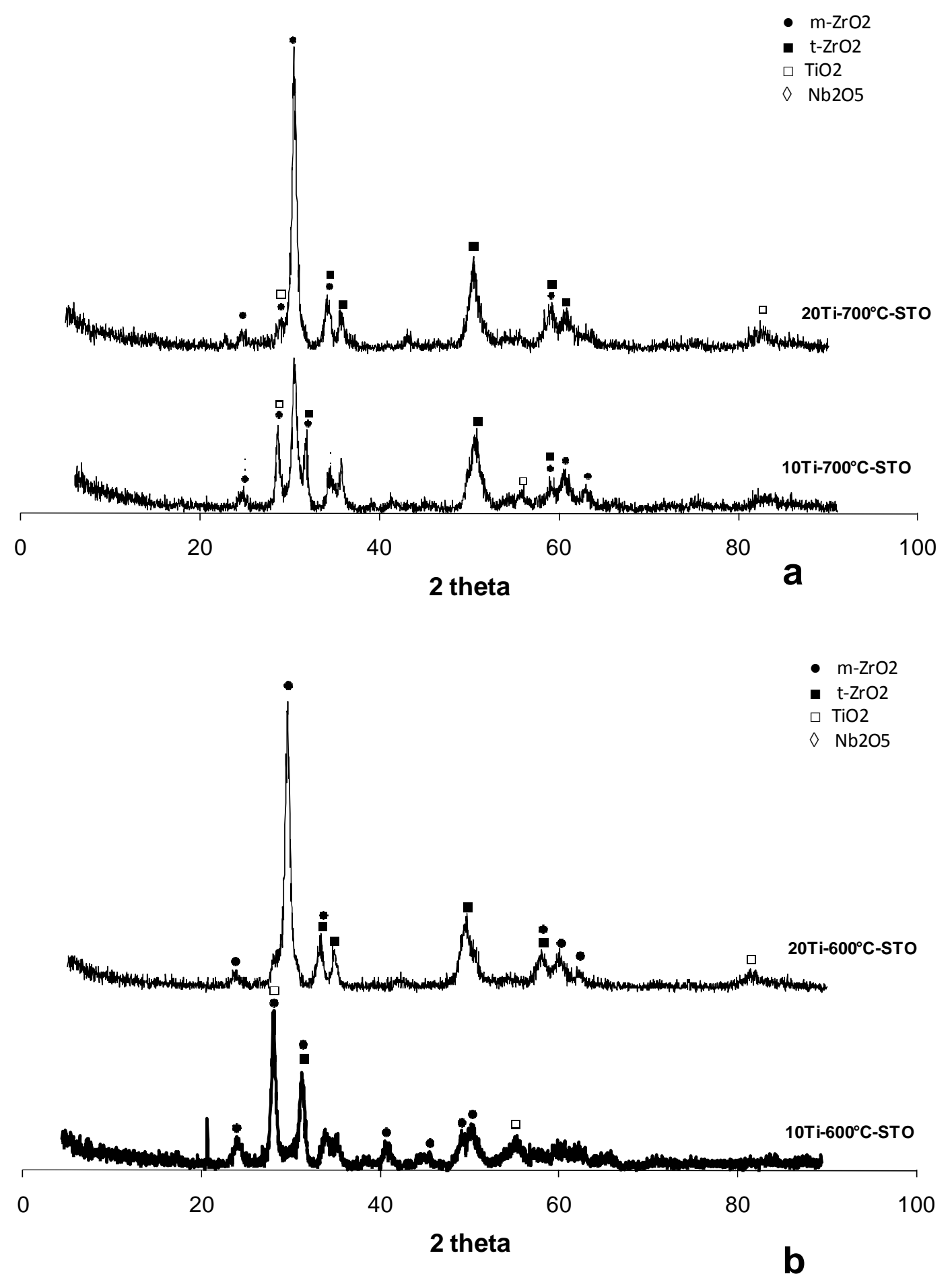

Figure 21. XRD patterns of the oxidation products of $20 \mathrm{Ti}$ and $10 \mathrm{Ti}$ alloys after $\mathrm{STO}$ at $700^{\circ} \mathrm{C}$ (a) and $600^{\circ} \mathrm{C}(\mathrm{b})$. 


\subsection{LTO Experiments}

Long term oxidation experiments were performed at 300,400 and $500^{\circ} \mathrm{C}$ (Figure 22), respectively, in order to obtain an understanding of the oxidation behavior of both alloys after the first cycle of 24 hours. From Figure 22, we observe that the alloy with better oxidation resistance at low temperature is $20 \mathrm{Ti}$ alloy. The fact that LTO experiments show that Ti has beneficial effect on the oxidation resistance is consistent with the STO experiments of this study. It may actually be assumed that the two phase structure, $\alpha-\mathrm{Zr}$ and $\beta-\mathrm{Nb}$, thus is the desirable structure for the compositions of the two selected alloys from the oxidation resistance point of view.

Furthermore, normally the oxidation processes progress as a function of time and it can show the same oxidation behavior throughout the experiment or it might change from linear to parabolic, and vice versa. It is obvious that both alloys show linear oxidation at lower temperatures; at 300 and $400^{\circ} \mathrm{C}$ the alloys are comparable in oxidation rate. Therefore, in order to better understand its oxidation mechanism, calculation of oxidation rate has been performed using the following equation:

$$
\mathrm{W}=\mathrm{k}_{l} \mathrm{t}
$$

$\mathrm{W}$ is the weight gain per unit area, $\mathrm{t}$ is the time, and finally $\mathrm{k}_{l}$ is oxidation rate or slope.

Table 4 shows the calculated oxidation rates, with the fit value $\left(\mathrm{R}^{2}\right)$, plus the mass gain per unit area after LTO at 400 and $500^{\circ} \mathrm{C}$ experiments. The oxidation rate at $300^{\circ} \mathrm{C}$ LTO was not calculated due to negligible oxidation. 


\section{Long Term Oxidation}

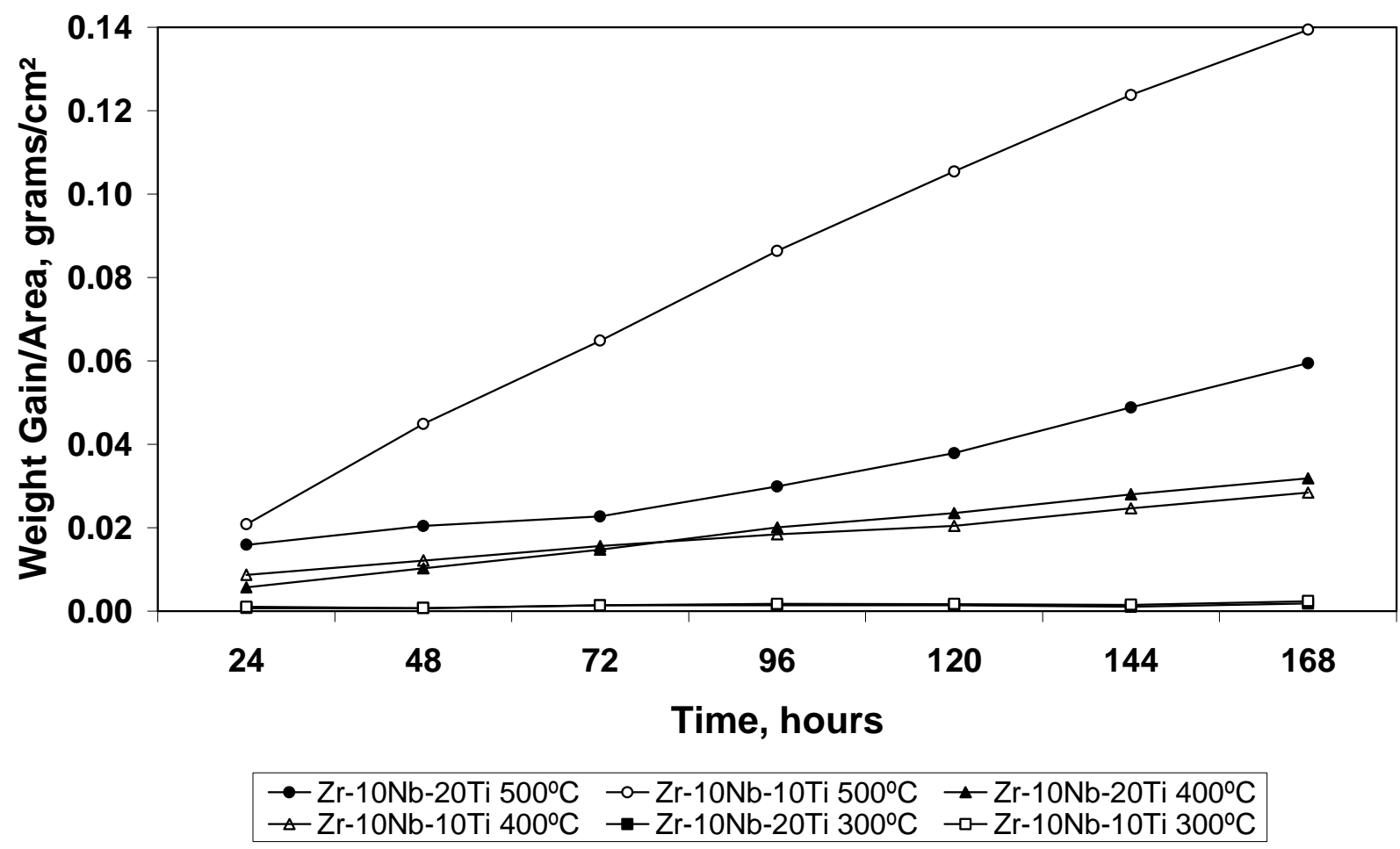

Figure 22. Cyclic long term oxidation (LTO) curves showing the isothermal weight change per unit area for 20Ti and 10Ti alloys for 7 cycles of 24 hours.

Table 4. Calculation of oxidation rates and mass gain per area values for the LTO experiments (20Ti and 10Ti, respectively).

\begin{tabular}{|c|c|c|c|}
\hline 20Ti LTO & Total mass gain per area & \multicolumn{2}{|c|}{ Oxidation rate constant } \\
\hline Temperature $\left({ }^{\circ} \mathrm{C}\right)$ & $m\left(\mathrm{mg} / \mathrm{cm}^{\wedge} 2\right)$ & $\mathrm{k} I\left(\mathrm{mg} / \mathrm{cm}^{\wedge} 2 / \mathrm{hr}\right)$ & $R^{\wedge} 2$ \\
\hline 400 & 84 & 4.4 & 0.9977 \\
\hline 500 & 157 & 7.2 & 0.9536 \\
\hline
\end{tabular}

\begin{tabular}{|c|c|c|c|}
\hline 10Ti LTO & Total mass gain per area & \multicolumn{2}{|c|}{ Oxidation rate constant } \\
\hline Temperature $\left({ }^{\circ} \mathrm{C}\right)$ & $\mathrm{m}\left(\mathrm{mg} / \mathrm{cm}^{\wedge} 2\right)$ & $\mathrm{k} I\left(\mathrm{mg} / \mathrm{cm} m^{\wedge} 2 / \mathrm{hr}\right)$ & $R^{\wedge} \mathbf{2}$ \\
\hline 400 & 82 & 3.2 & 0.9941 \\
\hline 500 & 402 & 19.8 & 0.9965 \\
\hline
\end{tabular}




\subsection{Hardness Measurements}

Hardness measurements were performed on selected samples to gain some understanding of the strength of the alloys in their as-received state and as a function of temperature, time, and microstructural features. It is well known that as a metal or alloy is annealed its hardness is reduced due to different factors, like grain growth, stress-relief or recovery in a previously cold worked alloy, and/or formation of weaker phases. ${ }^{[42]}$ After hardness measurements, we observe that tabulations (Table 5) of HRA measurements for the as-cast alloys shows a significantly lower hardness of $20 \mathrm{Ti}$ alloy when compared to $10 \mathrm{Ti}$; by converting to the more familiar Rockwell Hardness Scale C we observe that they have 21.5 and 30.9 HRC values, respectively; this is a significant difference in hardness. In order to better understand or get a better feeling of the hardness of this alloys we will use, as an example, the hardness value of common martensitic steel (HRC 55) and for tool steel (HRC 65). Moreover, we see a decrease in hardness as a function of increasing temperatures after STO experiments, which can be related to grain coarsening in the microstructure. ${ }^{[23]}$ Finally, several 2-hour heat treatments at different temperatures were performed on both alloys, and interestingly enough we observe an increase in hardness value of the 10Ti alloy as it goes from intermediate to higher temperatures (500 to $700^{\circ} \mathrm{C}$ ) (Table 5). An interesting correlation between increase in hardness and formation of $\beta \mathrm{Zr}$ cannot be avoided, inferring this higher temperature phase possesses higher strength than its lower temperature hexagonal form and the grain coarsening effect in hardness is overwhelmed by the formation of $\beta \mathrm{Zr}$ laths. Finally, a graph has been produced (Figure 23) by plotting HRA values as a function of temperature for the tested samples. This graph provides a better understanding of the effect of temperature, time, and microstructure on hardness of the 
zirconium alloys.

Table 5. Scale "A" Rockwell hardness values for both alloys after different oxidation experiments and heat treatments.

\begin{tabular}{|c|c|c|c|}
\hline \multicolumn{2}{|c|}{ 20Ti Alloy-STO } & \multicolumn{2}{c|}{ 10Ti Alloy-STO } \\
\hline Temperature, ${ }^{\circ} \mathrm{C}$ & HRA, avg. & Temperature, ${ }^{\circ} \mathrm{C}$ & HRA, avg. \\
\hline 25 & 61.1 & 25 & 65.7 \\
\hline 20Ti Alloy-STO & \multicolumn{2}{|c|}{ 10Ti Alloy-STO } \\
\hline Temperature, ${ }^{\circ} \mathrm{C}$ & HRA, avg. & Temperature, $^{\circ} \mathrm{C}$ & HRA, avg. \\
\hline 300 & 64.9 & 300 & 68.5 \\
\hline 350 & 66.1 & 350 & 65.2 \\
\hline 480 & 58.5 & 480 & 59.9 \\
\hline 485 & 60.0 & 485 & 55.4 \\
\hline 490 & 57.6 & 490 & 55.7 \\
\hline
\end{tabular}

\begin{tabular}{|c|c|}
\hline \multicolumn{2}{|c|}{ 10Ti Alloy-2hr. Heat Treatment } \\
\hline Temperature $^{\circ} \mathrm{C}$ & HRA, avg. \\
\hline 500 & 63.8 \\
\hline 555 & 56.2 \\
\hline 610 & 61.2 \\
\hline 660 & 67.1 \\
\hline
\end{tabular}

\begin{tabular}{|c|c|}
\hline \multicolumn{2}{|c|}{ 20Ti Alloy-2hr. Heat Treatment } \\
\hline Temperature, ${ }^{\circ} \mathrm{C}$ & HRA, avg. \\
\hline 450 & 66.6 \\
\hline 500 & 59.2 \\
\hline
\end{tabular}




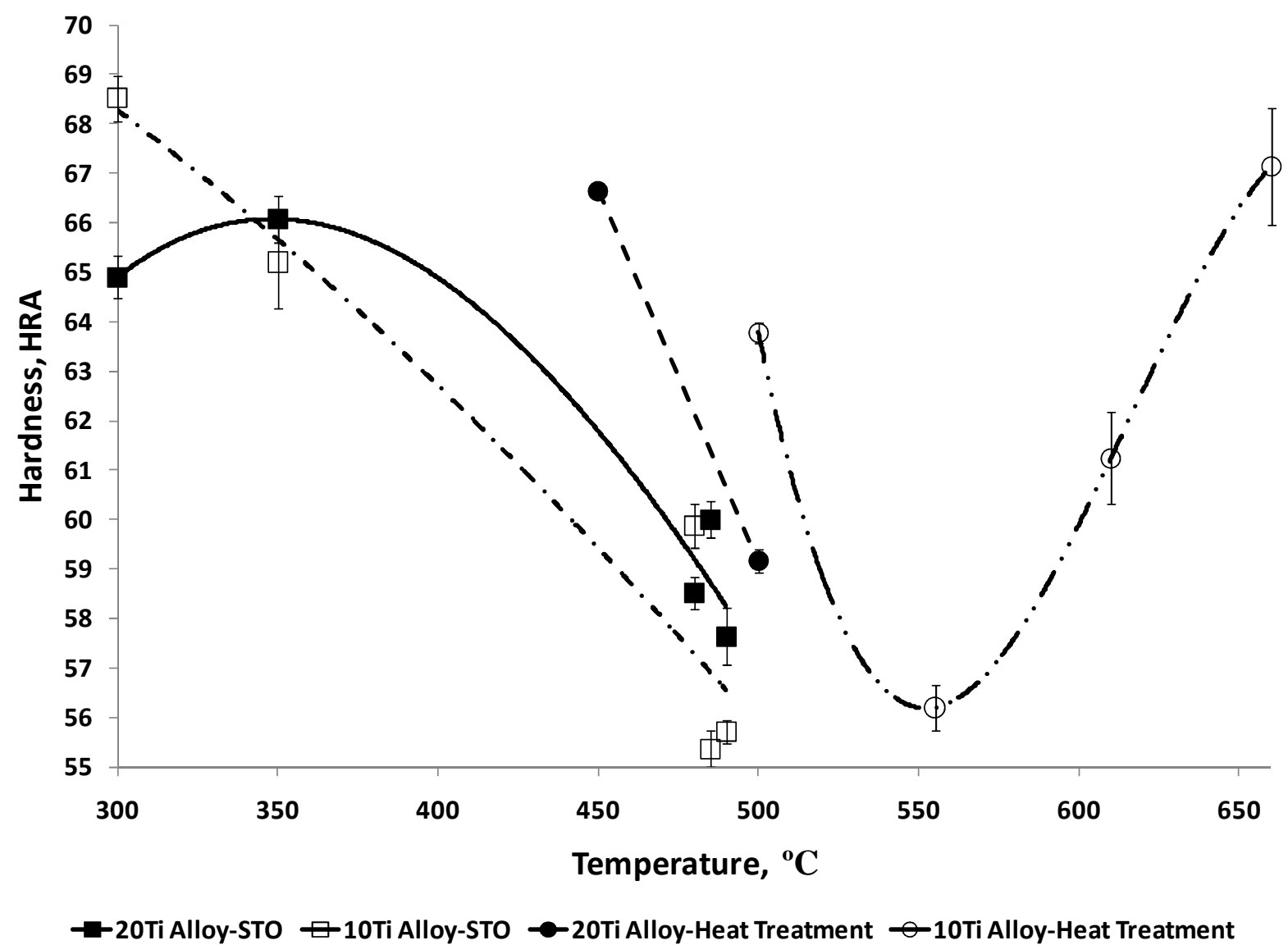

Figure 23. Plot of HRA values for 20Ti and 10Ti alloys as a function of temperature and time.

\subsection{Summary and Discussion}

This work presents the results obtained from the studies of the correlation between microstructure and oxidation behavior of $\mathrm{Zr}-10 \mathrm{Nb}-20 \mathrm{Ti}$ and $\mathrm{Zr}-10 \mathrm{Nb}-10 \mathrm{Ti}$ alloy; also some investigation of the mechanical properties of the alloys as a function of time, temperature and microstructure by Rockwell hardness measurements. 
The SEM images of the as-cast microstructures of the alloys, Fig.7, consisted of an $\alpha \mathrm{Zr}$ matrix, with presence of non-stable $\beta \mathrm{Zr}$ laths for both alloys, plus evidence of $\beta \mathrm{Nb}$ phase represented by spherical dark regions in the microstructure. XRD, Fig. 8, of both as-cast alloys confirms the presence of hexagonal and cubic zirconium in 10Ti; and $\alpha \mathrm{Zr}$ and $\beta \mathrm{Nb}$ in the 20Ti as-cast alloy. Furthermore, no evidence of peaks for $\beta Z \mathrm{r}$ in $20 \mathrm{Ti}$ alloy was detected, even though there were some laths present in the SEM micrograph. This might be due to very low content of the $\beta$ phase of zirconium in the as-cast microstructure. Pandat ${ }^{\mathrm{TM}} 7.1$, thermodynamic calculated ternary isotherms, predicts the presence of two stable phases for both alloys at room temperature, $\alpha \mathrm{Zr}$ and $\beta \mathrm{Nb}$. These phases were present in the microstructure of 20Ti as-cast alloy, plus some evidence of $\beta \mathrm{Zr}$. On the other hand, the 10Ti alloy showed a lot of $\beta \mathrm{Zr}$ laths, in Widmanstätten pattern, present in the hexagonal zirconium matrix. As previously explained, the presence of non-stable $\beta \mathrm{Zr}$ at low temperatures can be somewhat stabilized due to non-equilibrium fast cooling, and/or alloying elements that can have an effect on the stabilization of non-equilibrium phases. ${ }^{[19]}$ Therefore, the expected transformation that produce a thermodynamically stable microstructure (equilibrium microstructure) are usually obtained when extended heat treatments are performed at slightly higher temperatures in order to improve the mobility or diffusion of atoms species.

Short term oxidation experiments show that the slight improvement of oxidation resistance when comparing both alloys is due to higher concentration of titanium in the alloy. Furthermore, this effect can be observed as long as both alloys stay in the same phase region and contain the same microconstituents. For example, it appears that as long as the $\beta \mathrm{Nb}$ phase is present the alloy has better oxidation resistance than when this phase is not present; a similar 
situation was found in other studies where the improved corrosion resistance was attributed to the radiation-enhanced precipitation of $\beta-\mathrm{Nb}$ particles in the $\alpha-\mathrm{Zr}$ during radiation. ${ }^{[10,11]}$ Also, another study has found the presence of metallic $\beta \mathrm{Nb}$ precipitates in the region around the metal/oxide interface without oxidizing, and they concluded that the presence of this phases makes oxygen diffusion harder into the zirconium matrix, as a result it reduces the oxidation rate. ${ }^{[20,27]}$ On the other hand phase identification in this alloy system can become quite complex due to very little information on the $\mathrm{Zr}-\mathrm{Ti}-\mathrm{Nb}$ system and due to the formation of other intermediate and metastable phases in the $\mathrm{Zr}-\mathrm{Nb}$ system; for example there is another study which shows that a $\mathrm{Zr}-2.5 \mathrm{wt} \% \mathrm{Nb}$ alloy that was extruded at about $820^{\circ} \mathrm{C}$ had a two phase structure consisting of hexagonal $\alpha$-zirconium grains (containing up to about $1 \mathrm{wt} \% \mathrm{Nb}$ ) and a grain boundary network of metastable cubic $\beta$-zirconium (containing about $20 \mathrm{wt} \% \mathrm{Nb}$ ). ${ }^{[12]}$ Also, Griffiths, Winegar and Buyers $^{[13]}$ have found that the metastable $\beta$-zirconium transforms into other phases, like an intermediate hcp $\omega$-phase that forms after a 24 hour at $400^{\circ} \mathrm{C}$ stress-relief treatment in an autoclave. Moreover, another study shows the general fabrication route of CANDU pressure consisting of extrusion at about $800^{\circ} \mathrm{C}$, air cooling, cold draw to about $20-30 \%$ strain and autoclaving at $400^{\circ} \mathrm{C}$ for $24 \mathrm{~h}$. After extrusion it consists of $\sim 90 \%$ hcp $\alpha-\mathrm{Zr}$, which has $\mathrm{Nb}$ content $<1 \%$, and $\sim$ metastable bcc $\beta-\mathrm{Zr}$, which contains approximately $20 \% \mathrm{Nb}$. During autoclaving, $\beta-\mathrm{Zr}$ partially transforms to $\beta-\mathrm{Nb}(\sim 50 \% \mathrm{Nb}) .{ }^{[14]}$ Finally, Robson states that application of the model developed for the precipitation in zirconium niobium alloys at temperatures typical of reactor service $\left(250-350^{\circ} \mathrm{C}\right)$ suggests that in the absence of radiation effects, the precipitation kinetics are very sluggish. For example in a $\mathrm{Zr}-2.5 \mathrm{wt} \% \mathrm{Nb}$ alloy it is predicted to take over 100 years for the equilibrium fraction of $\beta-\mathrm{Nb}$ at $250^{\circ} \mathrm{C}$ to be reached. ${ }^{[15]}$ Therefore, phase composition might be slightly different than those reported for $\mathrm{Zr}-2.5 \mathrm{wt} \% \mathrm{Nb}$ 
due to the addition of $\mathrm{Ti}$ to the system, which is acting as a substitutional atom in solid solution and not forming any particular phase. Also, it appears that both alloys suffer from pest oxidation at higher temperatures probably due to the difference in the coefficient of thermal expansion of the oxide products. ${ }^{[16]}$ Furthermore, this study has provided more information on how the alloying elements might have a beneficial and/or adverse effect on the oxidation and mechanical properties of the alloys depending on a combination of factors like elemental concentration, microstructural features, such as stable phases. By using developed TTT (time-temperaturetransformation) diagrams for $\mathrm{Zr}-\mathrm{Nb}$ alloys heat treatments in an inert atmosphere might be performed in order to promote the formation of beneficial microstructures as related to oxidation and mechanical properties ${ }^{[17]}$.

Also, the formation of tetragonal zirconia along with stable monoclinic $\mathrm{ZrO}_{2}$ was detected in non-equilibrium conditions due to the high pressures produced by localized stresses present in the oxide scales. ${ }^{[33-35,49,51,54,55,78]}$

Furthermore, macrographs of both samples after short term oxidation experiments show the presence of black oxides in an island pattern on the surface of the metals. These oxides have been previously observed in other studies and identified as sub-oxides of zirconium containing high density of oxygen vacancies in the lattice. ${ }^{[68]}$

Finally, hardness measurements performed on both alloys after different oxidation experiments and heat treatments show an increased hardness values when the presence of $\beta \mathrm{Zr}$ is detected in the microstructure. 


\section{CHAPTER 5}

\section{CONCLUSIONS}

1. Zr-10Nb-20Ti alloys exhibits superior oxidation resistance, although small, compared to Zr$10 \mathrm{Nb}-10 \mathrm{Ti}$ based on the weight gain per unit area as a function of temperature for 24 hour heating cycle.

2. $\mathrm{Zr}-10 \mathrm{Nb}-10 \mathrm{Ti}$ exhibits linear oxidation curve up to nearly $600^{\circ} \mathrm{C}$ compared to $\mathrm{Zr}-10 \mathrm{Nb}-20 \mathrm{Ti}$ alloy whose linear oxidation characteristics end at $500^{\circ} \mathrm{C}$.

3. The increase in temperature up to $600^{\circ} \mathrm{C}$ for $\mathrm{Zr}-10 \mathrm{Nb}-10 \mathrm{Ti}$ alloy exhibiting good oxidation resistance is associated with the retention of $\beta \mathrm{Nb}$ (BCC) phase and development of $\beta \mathrm{Zr}$ (BCC) phase in the microstructure deteriorates the oxidation resistance.

4. The microstructural sequence predicted by the isotherms calculated by Pandat ${ }^{\mathrm{TM}} 7.1$ has been experimentally verified for both alloys, $\mathrm{Zr}-10 \mathrm{Nb}-10 \mathrm{Ti}$ and $\mathrm{Zr}-10 \mathrm{Nb}-20 \mathrm{Ti}$.

5. Linear oxidation behavior is found to be the oxidation mechanism taking place at lower temperatures.

6. Increased hardness is observed for the $\beta \mathrm{Zr}$ containing microstructures and for heat treatments at higher temperatures where the body center cubic form of zirconium is stabilized. 


\section{REFERENCES}

[1] K.C. Hari Kumar, P. Wollants, L. Delaey: Journal of Alloys and Compounds, 1994, vol. 206 pp. 125-126.

[2] PANDAT $^{\mathrm{TM}}$, Phase Diagram Calculation Software for Multicomponent Systems Computherm LLC, Madison, WI 53719, 2007.

[3] D.G. Hurst: Canada Enters the Nuclear Age, Mc-Gill-Queen's University press, 1997, pp. $194-196$

[4] J.P. Mardon, G. Garner, P. Beslu, D. Charquet, J. Senevat: in: Proceedings of the 1997 International Topic Meeting on LWR Fuel Performance, Portland, Oregon, 2-6 March, 1997, pp.405.

[5] G.P. Sabol, G.R. Kilp, M.G. Balfour, E. Roberts: ASTM STP 1023 (1989) 227. 2-6 March, 1997, p. 405.

[6] D.Q. Martins, W. R. Osório, M. E. P. Souza, R. Caram, A. Garcia: Electrochimica Acta 2008, vol. 53, p. 2816.

[7] W.Y. Guo, J. Sun, J.S. Wu: Materials Chemistry and Physics, 2009, vol. 113, p. 819. 
[8] J.A. Davidson, P. Kovacks: New Biocompatible, Low Modulus Titanium Alloy for Medical Implants, U.S. Patent no. 5, 169, 597, December 8, 1992, p. 4.

[9] J. C. Woo, S.K. Varma, R.N. Mahapatra: Effect of Ta and Zr Additions on the Oxidation Characteristics of Ti-44Al-xNb Alloys, Metallurgical and Materials Transactions A, 2003, vol. 34A, p. 2264.

[10] V.F. Urbanic, M. Griffiths: in: G.P. Sabol, G.D. Moan (Eds.), Zirconium in the Nuclear Industry: $12^{\text {th }}$ International Symposium, ASTM STP 1354, American Society for Testing and Materials, West Conshohocken, PA, 2000, p.641.

[11] O.T. Woo, G.M. McDougall, R.M. Hutcheon, V.F. Urbanic, M. Griffiths, C.E. Coleman: in: Zirconium in the Nuclear Industry: $12^{\text {th }}$ International Symposium, G.P. Sabol, G.D. Moan (Eds.), ASTM STP 1354, American Society for Testing and Materials, West Conshohocken, PA, 2002, p. 361.

[12] C.E. Lundin, R.H. Cox: USAEC Report No. 1/At (11-1)-752, 1960.

[13] M. Griffiths, J.E. Winegar, A. Buyers: Journal of Nuclear Materials, 2008, vol. 383, p. 30

[14] R.A. Holt: J. Nucl. Mater., 2008, vol. 372, p. 182.

[15] J.D. Robson: Journal of Nuclear Materials, 2008, vol. 377, p. 421. 
[16] Y.S. Touloukian: Thermophysical properties of matter, IFI/Plenum: New York-Washington, 1970, vol. 13, pp. 324, 393 and 452.

[17] M. Griffiths, J.E. Winegar, A. Buyers: Journal of Nuclear Materials, 2008, vol. 383, pp. 28.

[18] V.F. Urbanic, R.W. Gilbert: in: Proceedings of a Technical Committee Meeting organized by the International Atomic Energy Agency, Portland, Oregon, September 1989, IWGFPT34, p. 262.

[19] G. F. Vander Voort: Metallography Principles and Practice, Materials Science and Engineering Series, ASM International, p. 701.

[20] A. Gutierrez, M.F. López, J.A. Jiménez, C. Morant, F. Paszti, and A. Climent: Surface and interface Analysis, 2004; vol. 36, pp. 978-979.

[21] T. Arima, K. Miyata, K. Idemitsu, Y. Inagaki: Progress in Nuclear Energy, 2009, vol. 51, pp. 308-309.

[22] T.L. Brown, H.E. LeMay, B.E. Bursten, J.R. Burdge: Chemistry: The Central Science, $9^{\text {th }}$ Ed., Pearson Education Inc., Upper Saddle River, NJ, 2003, p. 128. 
[23] W.D. Callister, Jr.: Materials Science and Engineering: An Introduction, $5^{\text {th }}$ Ed., John Wiley

\& Sons, Inc., New York-Chichester-Weinheim-Brisbane-Singapore-Toronto, 2000, pp. 563, 592.

[24] R.C. Weast, M.J. Astle, W.H. Beyer: CRC Handbook of Chemistry and Physics, $65^{\text {th }}$ Ed., CRC Press, Inc., Boca Raton, Florida, 1985, p. B-39.

[25] N. Birks and G.H. Meier: Introduction to High Temperature Oxidation of Metals, Edward Arnold Ltd., 1983, pp. 54, 55, 60.

[26] D.R. Lide (ed): CRC Handbook of Chemistry and Physics, 84th Edition. CRC Press, Inc., Boca Raton, Florida, 2003; Section 10, Atomic, Molecular, and Optical Physics; Ionization Potentials of Atoms and Atomic Ions.

[27] J.E. Huheey, E.A. Keiter, and R.L. Keiter: Inorganic Chemistry: Principles of Structure and Reactivity, 4th edition, HarperCollins, New York, USA, 1993.

[28] A.M. James, M.P. Lord: Macmillan's Chemical and Physical Data, Macmillan, London, UK, 1992.

[29] G.L. Miller, Zirconium: Metallurgy of the Rare Metals, vol. 2, Academic Press Inc., New York, Butter Worths Scientific Publication, London 1954. 
[30] G.L. Miller, Tantalum and Niobium: Metallurgy of the Rare Metals, vol. 6, Academic Press Inc., New York, Butter Worths Scientific Publication, London, 1959.

[31] A.D. McQuillan, and M.K. McQuillan, Titanium: Metallurgy of the Rare Metals, vol. 4, Butter Worths Scientific Publication, London, 1956.

[32] M.J. Benett, A.T. Tuson: J. Mater. Sci. Eng. A 116, 1989, p. 79.

[33] K. Przybylski, A.J. Farratt-reed, F.J. Yurek: J. Electrochem. Soc. 135, 1988, p. 509.

[34] H.G. Kim, Y.H. Jeong, T.H. Kim: J. Nucl. Mater. 326, 2004, p. 125.

[35] Y.H. Jeong, H.G. Kim, D.J. Kim, B.K. Choi, J.H. Kim: J. Nucl. Mater. 323, 2003, p. 72.

[36] H. Anada, K. Takeda, S. Hagi, T. Murata, A. Oe, T. Miyashita: Out-of-Pile Corrosion Behavior and Corrosion Mechanism of NDA for High Burn-up Fuel of PWR, in: Proceeding of the ANS International Topical Meeting on LWR Fuel Performance, IAEA, Park City, 2000, pp. 445-456.

[37] O.S. Ivanov, V.K. Grigorovich: Proceeding of the Second United Nations International Conference on the Peaceful Uses of Atomic Energy, Geneva, vol. E-14/P/2046, 1958, pp. 34-51. 
[38] R.S. Ambartsumyan, A.A. Kiselev, R.V. Grebennikov, V.A. Myshkin, L.J. Tsuprun, A.F. Nikulina: Proceeding of the Second United Nations International Conference on the Peaceful Uses of Atomic Energy, Geneva, vol. E-14/P/2044, 1958, pp. 12-33.

[39] S. Abolhassani, R. Restani, T. Rebac, F. Groeschel, W. Hoffelner, G. Bart, W. Goll, F. Aeschbach: J. ASTM Int. 2, 2005, p. 1.

[40] P. Bossis, J. Thomazet, F. Lefebvre, in: Zirconium in the Nuclear Industry: Thirteenth International Symposium, 2002, pp. 190-217.

[41] E18-07, Standard Test Methods for Rockwell Hardness of Metallic Materials, ASTM International, 2007.

[42] R.E. Reed-Hill: Physical Metallurgy Principles, $3^{\text {rd }}$ Ed., PWS Publishing Company, 1991, pp. 229.

[43] A.P. Zhilyaev, J.A. Szpunar: Infuence of stress developed due to oxide layer formation on the oxidation kinetics of Zr-2.5\% Nb alloy, Journal of Nuclear Materials 264, 1999, pp. 327-328.

[44] A. Lyapin, L.P.H. Jeurgens, E.J. Mittemeijer: Effect of temperature on the initial, thermal oxidation of zirconium, Acta Materialia 53, 2005, pp. 2925-2935. 
[45] L.P.H. Jeurgens, A. Lyapin, E.J. Mittemeijer: The mechanism of low-temperature oxidation of zirconium, Acta Materialia 53, 2005, pp. 4871-4879.

[46] H. Ardelean , I. Frateur, P. Marcus: Corrosion protection of magnesium alloys by cerium, zirconium and niobium-based conversion coatings, Corrosion Science 50, 2008, pp. 1907-1918.

[47] H. Ardelean , I. Frateur, S. Zanna, A. Atrens, P. Marcus: Corrosion protection of AZ91 magnesium alloy by anodizing in niobium and zirconium-containing electrolytes, Corrosion Science, 2009, Journal Homepage: www.elsevier.com/locate/corsci.

[48] K. Sridharan, S.P. Harrington, A.K. Johnson, J.R. Licht, M.H. Anderson, T.R. Allen: Oxidation of plasma surface modified zirconium alloy in pressurized high temperature water Materials and Design 28, 2007, pp. 1177-1185.

[49] M. Steinbrïck: Oxidation of Zirconium Alloys in Oxygen at High Temperatures up to $1600^{\circ} \mathrm{C}$, Oxid Met 70, 2008, pp. 317-329.

[50] V. S. Rudnev, K. N. Kilin, P. M. Nedozorov, A. Yu. Ustinov, T. P. Yarovaya, and T. A. Kaidalova: Oxide-Phosphate Layers with Zirconium Compounds on Titanium, Protection of Metals, Vol. 43, No. 6, 2007, pp. 542-547.

[51] Ch. Valet, D. Ciosmak, M. Lallemant: Spatiotemporal dynamics in the oxidation of groups IV-V metals: study of zirconium, Solid State Ionics 101-103, 1997, pp. 769-774. 
[52] R.L. Tapping, P.K. Chan a, P.R. Norton, C.-S. Zhang: SIMS studies of the corrosion of zirconium, International Journal of Mass Spectrometry and Ion Processes 146/147, 1995, pp. 7589.

[53] S.J. Li, R. Yang, S. Li, Y.L. Hao, Y.Y. Cui, M. Niinomi, Z.X. Guo: Wear characteristics of Ti-Nb-Ta-Zr and Ti-6Al-4V alloys for biomedical applications, Wear 257, 2004, pp. 869-876.

[54] D. Hudson, A. Cerezo, G. D.W.Smith: Zirconium oxidation on the atomic scale, Ultramicroscopy 109, 2009, pp. 667-671.

[55] J. S. Moya, M. Diaz, J. F. Bartolome, E. Roman, J. L. Sacedon, J. Izquierdo: Zirconium Oxide Film Formation On Zircaloy By Water Corrosion, Acta mater. 48, 2000, pp. 4749-4754.

[56] P. Berger, R. El Tahhann, G. Moulin, M. Viennot: High temperature oxidation of zirconium and zircaloy-4 under applied load: Nuclear microprobe study of the growth of the oxide, Nuclear Instruments and Methods in Physics Research B 210, 2003, pp. 519-525.

[57] N. Stojilovic, E.T. Bender, R.D. Ramsier: Surface chemistry of zirconium: Review, Progress in Surface Science 78, 2005, pp. 101-184.

[58] R.L. Tapping, P.K. Chan, P.R. Norton, C.-S. Zhang: SIMS studies of the corrosion of zirconium, International Journal of Mass Spectrometry and Ion Processes 146/147, 1995, p. 76. 
[59] R. Arroyave, L. Kaufman, T. W. Eagar: Thermodynamic Modeling of the Zr-O System, Calphad, Vol. 26, No. 1, 2002, pp. 95-118.

[60] V. N. Konev, A. L. Nadolskii, and L. A. Minyacheva: Mechanism of Oxygen Dissolution in Metallic Zirconium, Oxidation of Metals, Vol. 47, Nos. 3/4, 1997 pp. 237-245.

[61] V. I. Shevtsov, A. E. Valov, M. G. Vlasov, E. I. Gusachenko, L. N. Stesik: HighTemperature Oxidation of an Alloy of Zirconium And Niobium, Combustion, Explosion, and Shock Waves, Vol. 33, No. 6, 1997, pp.647-651.

[62] I. V. Oryshich, N. E. Poryadchenko, and N. P. Brodnikovskii: High-Temperature Oxidation of Intermetallics Formed by Group IV Transition Metals With Chromium, Powder Metallurgy and Metal Ceramics, Vol. 43, Nos. 9-10, 2004, pp. 497-503.

[63] H. Frank, Z. Weishauptova, V. Vrtilkova: Influence of protecting gel film on oxidation of zirconium alloys, Journal of Nuclear Materials 360, 2007, pp. 282-292.

[64] Y. Nishino, A.R. Krauss, Y. Lin, D.M. Gruen: Initial oxidation of zirconium and Zircaloy-2 with oxygen and water vapor at room temperature, Journal of Nuclear Materials 228, 1996, pp. 346-353. 
[65] A. Froideval, S. Abolhassani, D. Gavillet, D. Grolimund, C. Borca, J. Krbanjevic, C. Degueldre: Microprobe analysis of neutron irradiated and autoclaved zirconium niobium claddings using synchrotron-based hard X-ray imaging and spectroscopy, Journal of Nuclear Materials 385, 2009, pp. 346-350.

[66] B. Cox: Zirconium oxidation at low temperature and pressure (Comments on a paper by X. Iltis et al., J. Nucl. Mater. 209, 1994, p. 180): Letter to the Editors, Journal of Nuclear Materials 218, 1995, pp. 261-264.

[67] D. Melconian, M. Trinczek, A. Gorelov, W.P. Alford, J.A. Behrd, J.M. D’Auria, M. Dombsky, U. Giesend, K.P. Jackson, T.B. Swanson, W. Wong: Release of ${ }^{37} \mathrm{~K}$ from catcher foils, Nuclear Instruments and Methods in Physics Research A 538, 2005, pp. 93-99.

[68] D. Q. Peng, X. D. Bai, F. Pan, H. Sun, B. S. Chen: Influence of Implanted Aluminum Ions on the Oxidation Behavior of M5 Alloy at $500^{\circ} \mathrm{C}$, Oxidation of Metals, Vol. 65, Nos. 5/6, June 2006, pp. 377-390.

[69] A. Froideval, C. Degueldre, C.U. Segre, M.A. Pouchon, D. Grolimund: Niobium speciation at the metal/oxide interface of corroded niobium-doped Zircaloys: A X-ray absorption near-edge structure study, Corrosion Science 50, 2008, pp. 1313-1320. 
[70] X.W. Chen, X.D. Bai, P.Y. Deng, D.Q. Peng, B.S. Chen: Electrochemical behavior of niobium-implanted zircaloy-4 induced by heat treatment, Nuclear Instruments and Methods in Physics Research B 211, 2003, pp. 512-518.

[71] M. Grobe, E. Lehmann, M. Steinbrück, G. Kühne, J. Stuckert: Influence of oxide layer morphology on hydrogen concentration in tin and niobium containing zirconium alloys after high temperature steam oxidation, Journal of Nuclear Materials 385, 2009, pp. 339-345.

[72] M.T. Jovanović, R.L. Eadie, Y. Maa, M. Anderson, S. Sagat, V. Perovic: The effect of annealing on hardness, microstructure and delayed hydride cracking in $\mathrm{Zr}-2.5 \mathrm{Nb}$ pressure tube material, Materials Characterization 47, 2001, pp. 259-268.

[73] N. I. Taluts, A. V. Dobromyslov: Structure of Quenched Zr-Pd Alloys and the Formation of the $\omega$ Phase in Zirconium Alloys, The Physics of Metals and Metallography, Vol. 104, No. 6, 2007, pp. 601-610.

[74] X.W. Chen, X.D. Bai, R.H. Yu, Q.G. Zhou, B.S. Chen: Studies on the oxidation behavior of niobium-implanted Zircaloy-4 at $500{ }^{\circ} \mathrm{C}$, Journal of Nuclear Materials 306, 2002, pp. 190-193.

[75] R.F. Domagalla, D.J. McPherson : Trans. AIME 200, 1954, p. 238.

[76] J.P. Abriata, J. Garcés, R. Versaci, Bull: Alloy Phase Diagrams 7, 1986, p. 116. 


\section{CURRICULUM VITAE}

Clemente José Parga Arronte was born on March 25, 1984 in El Paso, Texas, USA. He is the eldest of three sons of Clemente Virgilio Parga Salas and María Amparo Arronte Quiñonez He completed his high school education at Instituto Frances Guadalupe located in Cd. Juárez, Chihuahua, México in May 2002. In the fall of that same year he enrolled at The University of Texas at El Paso and graduated in May 2007 with a B.S. degree in metallurgical and Materials Engineering. During he's B.S. degree he spent the summer of 2006 as an intern at the Argonne National Laboratory, Argonne, Illinois under the lead of Dr. Shailendra K. Varma. Upon graduation he worked in the industry as an Aluminum Brazing Engineer at Visteon Coclisa Plant in Cd. Juárez, Chihuahua, México. In the spring of 2008 he enrolled in the M.S. program of the Metallurgical and Materials Engineering Department at UTEP and got a research assistantship with Dr. S.K. Varma under whom he authored a publication and made a poster and oral presentation at the Materials Science \& Technology Conference in Pittsburgh, Pennsylvania. He has been granted with a Contrat de Thèse (CTBU), in order to prepare a doctoral thesis at CEA (Commissariat à l'ènergie atomique)/Cadarache, St Paul lez Durance, France for the Dèpartment

de Technologie Nuclèaire (DTN) over the following subject: "Measurement of very high temperatures (2000-3500K) - Application to Nuclear Reactor Safety"

Permanent Address: 513 Twin Oaks Place

El Paso, TX, USA

This thesis was typed by Clemente J. Parga 